Copyright

by

Yang Wang 2013 
The Thesis Committee for Yang Wang

Certifies that this is the approved version of the following thesis:

Shear Velocity Structure and Mineralogy of the Transition Zone beneath the East Pacific Rise

APPROVED BY
SUPERVISING COMMITTEE:

Supervisor:

Stephen P. Grand

Jung-Fu Lin

Luc Lavier 


\title{
Shear Velocity Structure and Mineralogy of the Transition Zone beneath the East Pacific Rise
}

\author{
by \\ Yang Wang, B.S. \\ Thesis \\ Presented to the Faculty of the Graduate School of \\ The University of Texas at Austin \\ in Partial Fulfillment \\ of the Requirements \\ for the Degree of
}

Master of Science in Geological Sciences

The University of Texas at Austin

May, 2013 


\section{Acknowledgements}

I would like to thank the many people who directly and indirectly helped make this work possible. First of all, I would like to thank my supervisor, Dr. Stephen P. Grand, for his support, advice and understanding for such a long term.

I would like to thank my undergraduate advisor, Dr. Sidao Ni for inspiring me with his passion of earthquake seismology.

I would like to thank Dr. Jung-Fu Lin for his invaluable advice on mineral physics aspect of my work.

I would like to thank both Dr. Jung-Fu Lin and Dr. Luc Lavier for being on my committee and reviewing my thesis.

Finally, I would like to thank my officemates-Youcai Tang and Yu Xia for their encouragement and support for a long time. 


\title{
Abstract \\ Shear Velocity Structure and Mineralogy of the Transition Zone beneath the East Pacific Rise
}

\author{
Yang Wang, M.S.GEO.SCI. \\ The University of Texas at Austin, 2013 \\ Supervisor: Stephen P. Grand
}

Models of seismic velocity as a function of depth through the upper mantle provide some of the strongest constraints on the mineralogy and composition of the mantle. Although receiver function studies have provided new information on the depths of upper mantle discontinuities they do not provide as much information on seismic gradients and velocities. The waveforms and travel times of upper mantle turning waves provide the strongest constraints on vertical variations in upper mantle velocity although in the past they suffered from the lack of dense profiles of data sampling a single part of the upper mantle that would minimize effects of 3D variations in velocity. Here we model three dense profiles of triplicated upper mantle broadband S and SS waves recorded by USArray, Canadian and NARS-Baja stations located in western North America. Earthquakes along the East Pacific Rise were recorded along profiles within $5^{\circ}$ back azimuth windows and with stations at a maximum of $.5^{\circ}$ separation. The distance range covered is from $30^{\circ}$ to $60^{\circ}$ and thus the waves sample the mantle from the lithosphere to depths near $1000 \mathrm{~km}$. The data were inverted using a conjugate gradient algorithm that utilizes the reflectivity synthetic technique. The results show a much smaller gradient within the transition zone than the PREM model with larger jumps in velocity at the $410 \mathrm{~km}$ and 
$660 \mathrm{~km}$ depth discontinuities. These results are consistent with velocities predicted for a pyrolite composition mantle transition zone. Compositional models with lower olivine content, such as piclogite, are not consistent with our seismic model. 


\section{Table of Contents}

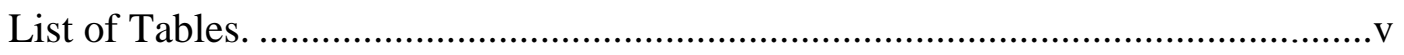

List of Figures ...................................................................................... vi

Chapter $1:$ Introduction ..............................................................................

Chapter 2: Data and Observation..................................................................

Chapter 3: Inversion ............................................................................ 12

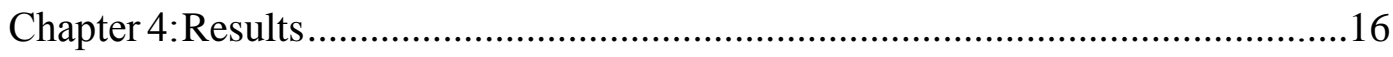

Chapter 5: Resolution Tests..........................................................................21

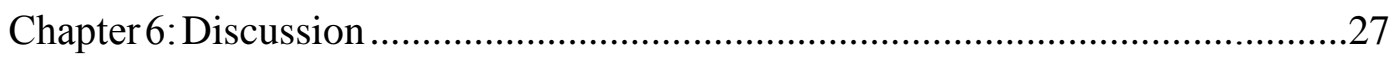

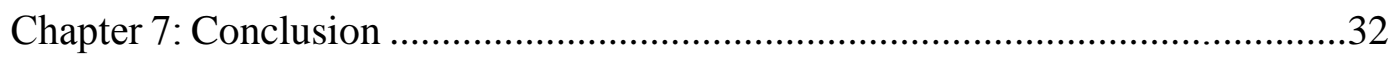

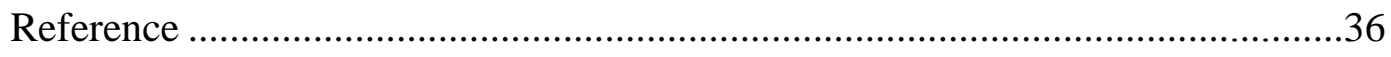




\section{List of Tables}

Table 1: Parameters of the three earthquakes from the Harvard Centroid Moment

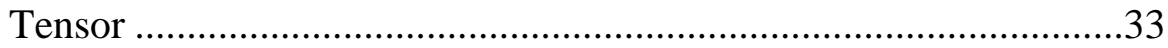

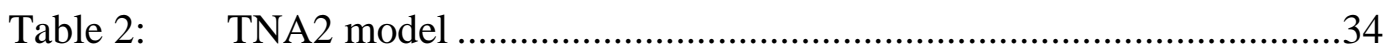




\section{List of Figures}

Figure 1: Comparison of the PREM seismic shear velocity model and the AK135 seismic model with predictions of shear velocity assuming a pyrolite composition along a $1600^{\circ} \mathrm{K}$ adiabat. .3

Figure 2: $\quad$ Raypaths and travel time curve for a simple model of shear velocity wih

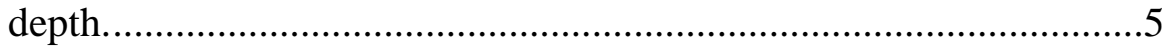

Figure 3: $\quad$ A profile of synthetic seismograms using the TNA model (Grand and Helmberger, 1984) between $35^{\circ}$ and $60^{\circ}$ distance.............6 6

Figure 4: Location of stations, earthquakes and the midpoints between stations and the earthquakes for the data inverted for seismic structure.

Figure 5: Comparison of seismic data from earthquake A with synthetic seismograms computed using model TNA, the PREM model, and the AK135 model.

Figure 6: Inversion results for shear velocity as a function of depth using data from earthquakes $\mathrm{A}, \mathrm{B}$, and $\mathrm{C}$. 15

Figure 7: Comparison of data from profiles produced by earthquakes A, B, and C to synthetic seismograms computed using the inversion results from figure 6 17

Figure 8: Comparison between the TNA2 model and previously published models of transition zone shear velocity as a function of depth. 18

Figure 9: Starting models used to test resolution of the velocity gradient.......20

Figure 10: Comparison of observed tangential seismograms and synthetic seismograms using the high gradient resolution test models. 
Figure 11: Comparison of observed tangential seismograms and synthetic seismograms using the low gradient resolution test models...........................................23

Figure 12: Starting models used to test resolution of the velocity jumps over the $410 \mathrm{~km}$ and $660 \mathrm{~km}$ discontinuities.

Figure 13: Comparison of shear velocity model TNA2 with predictions of shear velocity assuming a pyrolite composition along a $1600^{\circ} \mathrm{K}$ adiabat.

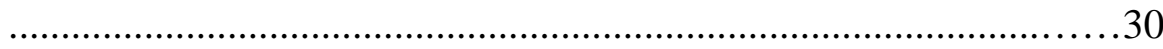

Figure 14: Comparison of model TNA2 with the iPREF model........................31 


\section{Chapter 1: Introduction}

The mantle transition zone is bound by two significant and ubiquitous global seismic velocity discontinuities near $410 \mathrm{~km}$ and $660 \mathrm{~km}$ depth, which are believed to result from phase transitions. The $410 \mathrm{~km}$ discontinuity is due to the phase transition of olivine to wadsleyite, while the $660 \mathrm{~km}$ discontinuity is caused by the endothermic phase change from ringwoodite to perovskite and magnesiowustite (e.g., Bina and Helffrich, 1994). There might also be a small seismic discontinuity near $520 \mathrm{~km}$ depth, in light of recent observations (Deuss and Woodhouse, 2001; Shearer 1990) that is due to the wadsleyite to ringwoodite transition. High pressure mineral physics results have led to efforts to interpret upper mantle seismic models in terms of mineralogy and chemical composition. (e.g. Cammarano et al. 2003, 2005a, 2005b; Li and Liebermann, 2007; Anderson and Bass, 1984; Weidner and Ito, 1987; Ita and Stixrude, 1992) For example, the size of the jumps in velocity near $410 \mathrm{~km}$ and $660 \mathrm{~km}$ depth should place constraints on the amount of olivine in the upper mantle using mineral physics results for the difference in elastic velocities of olivine and wadsleyite. Such comparisons are complicated in that seismic velocity also depends on temperature, water content, as well as other factors. Bass and Anderson, (1984) were among the first to note that the "standard" model for the mineralogy of the upper mantle, the pyrolite model (Ringwood, 1975), did a poor job of fitting shear wave velocity in the transition zone. Pyrolite consists of olivine ( $\sim 55-60 \%$ by weight) with lesser amounts of clinopyroxene, orthopyroxene, and garnet. Bass and Anderson (1984) introduced the term piclogite as an alternative mineral composition for the mantle transition zone that they claimed better fit seismic velocities. The piclogite model has much less olivine than pyrolite $(<40 \%)$ and more clinopyroxene and garnet (Bass and Anderson, 1984). The Bass and Anderson (1984) study was controversial (Bina and Wood, 1987) as the mineral physics data used involved extensive pressure and temperature extrapolations. 
More recently mineral physics studies have confirmed earlier work that showed there is a difficulty matching shear wave seismic models for the upper mantle transition zone to simple mineral model predictions. Li and Liebermann (2007), show that a pyrolite model along a $1600 \mathrm{~K}$ adiabat does not match the velocity jump at $410 \mathrm{~km}$ nor the transition zone shear velocity gradient when compared to standard seismic reference models such as PREM (Dziewonski and Anderson, 1981) or AK135 (Kennett et al., 1995). Li and Liebermann, (2007) suggest that further investigation of the water content in the mantle and its effect on elastic properties, as well as consideration of other mantle compositional models over the depth range $400 \mathrm{~km}$ to $650 \mathrm{~km}$, are needed. Irifune et al. (2008) first combined in situ X-ray and ultrasonic measurements on realistic mantle compositions under pressure and temperature conditions of the mantle transition region. The experiments show that a pyrolite composition model predicts significantly lower shear-wave velocities in the lower part of the transition zone than standard seismic models show, suggesting possible subadiabatic temperatures or the existence of a layer of harzburgite-rich material supplied by subducted slabs stagnant at these depths. Irifune et al. (2008) also show predicted shear velocities for a piclogite composition but the comparison to seismic models is still poor assuming a uniform composition across the entire transition zone. Xu et al. (2008) point out the same discrepancies between shear velocity models and predictions of mineral physics for simple models of chemical composition. In their work they note the difference between a mechanical mixture of basalt and harzburgite versus an equilibrium pyrolite composition but in both cases the jump in velocity at $410 \mathrm{~km}$ depth is predicted to be larger than standard seismic models. They also find that shear velocity below $660 \mathrm{~km}$ depth is predicted to be lower than seismic models show for an overall pyrolitic composition. Comparisons of the Li and Liebermann, (2007), Irifune et al. (2008) and Xu et al. (2008) models to PREM and AK135 are shown in figure 1. It is clear that at present there is no good agreement between published reference shear wave velocity models of the transition zone and seismic velocity predictions made using standard mineralogical models. It is not clear what the causes of the discrepancies are, but one possibility is that the seismic models 
used in these comparisons are not accurate. Consequently, high resolution radial seismic velocity models are required to refine models of the mineralogy of the upper mantle.

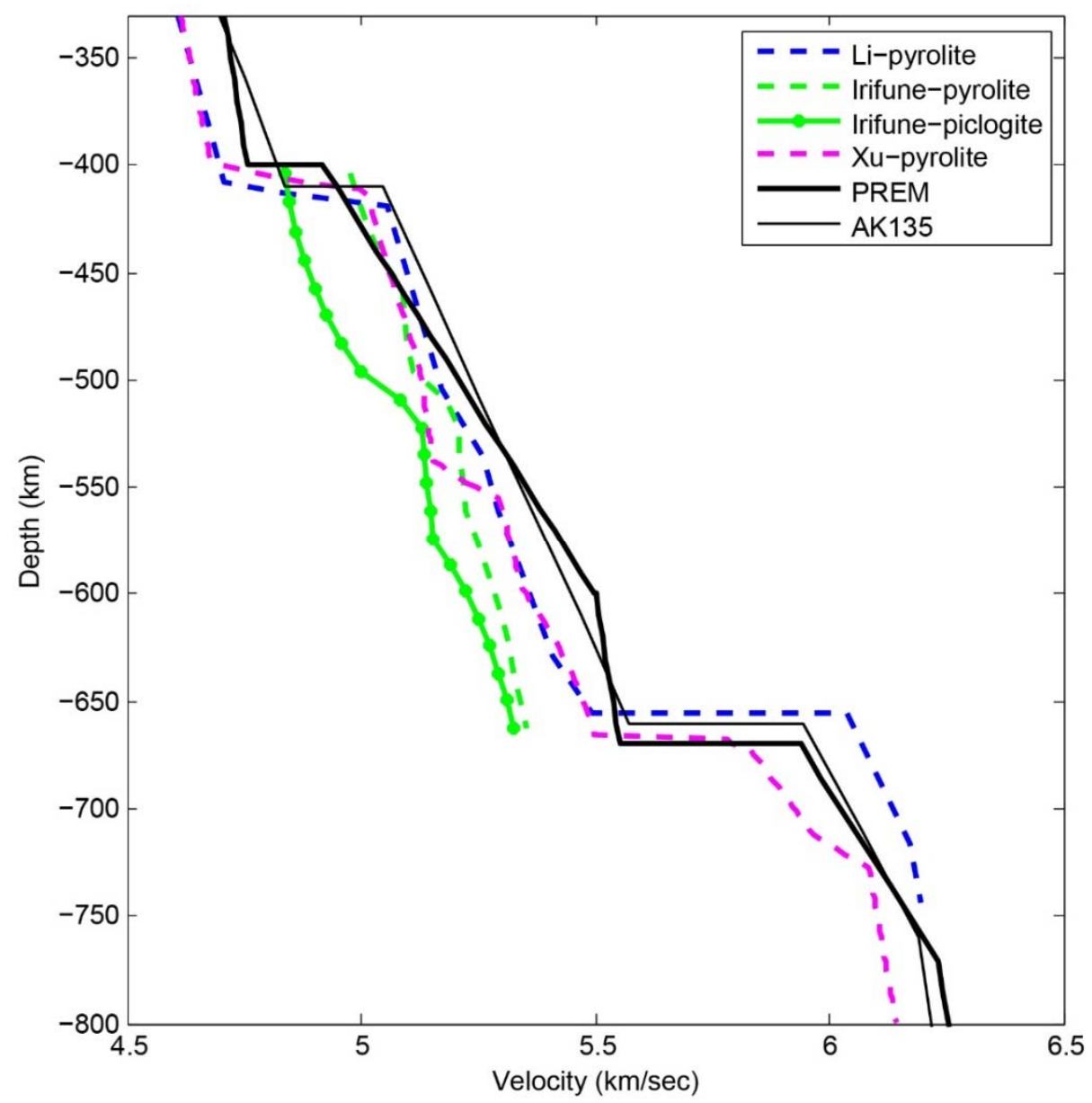

Figure 1. Comparison of the PREM seismic shear velocity model (black thick line) and the AK135 seismic model (black thin line) with predictions of shear velocity assuming a pyrolite composition along a $1600^{\circ} \mathrm{K}$ adiabat. The green dashed line is the prediction from Irifune et al., (2008), the purple dashed line is from Xu et al., (2008) and the blue dashed line is from Li et al., (2007). A prediction of shear velocity assuming a piclogite compostion from Irifune at al., (2007) is also shown as a solid green line. 
Seismic data provide a tremendous amount of information about the Earth's interior. Love and Rayleigh surface waves provide some of the best constraints on the shallow part of the mantle (less than about $200 \mathrm{~km}$ depth) but the resolution decreases below $300 \mathrm{~km}$. Body wave arrivals are more sensitive to deeper structure. The use of underside reflected precursors of SS and PP waves (Shearer and Masters, 1992; Shearer, 1993; Shearer and Flanagan, 1999; Duess et al., 2006) or converted Ps or Sp waves have been powerful techniques to investigate upper mantle seismic structure (e.g. Ai and Zheng, 2003; Dueker and Sheehan, 1997). These studies provide strong constraints on topography of upper mantle discontinuities and impedance contrast across the discontinuities. Although it is possible to determine the velocity jump across the discontinuity by using the amplitude versus angle of incidence of reflected or converted waves, there are usually high uncertainties in the results. Also, these techniques provide no information on velocity gradients between discontinuities.

The travel times and waveforms of triplicated shear waves that turn within the upper mantle have the potential to better constrain $\mathrm{S}$ velocity structure. For a source at the surface, S waves from 15 to 30 degree distance bottom above $800 \mathrm{~km}$ depth while the same triplicated waves can be seen in SS waves at double the distance. As an example of wave sampling, figure 2 a shows a simple shear velocity model based on the published seismic model, TNA (Grand and Helmberger, 1984), as well as a travel time curve (figure 2b) for that model. Ray paths for an SS wave recorded at $47^{\circ}$ distance (figure 2c) are also shown. Due to discontinuities near $410 \mathrm{~km}$ and $660 \mathrm{~km}$ depth, multiple arrivals are produced at certain distances, at $47^{0}$ distance, waves turning within the transition zone as well as a wave that turns below $660 \mathrm{~km}$ depth arrive at nearly the same time resulting in a complicated waveform. Figure 3 shows a profile of synthetic seismograms computed for the model shown in figure $2 \mathrm{a}$. Branch $\mathrm{AB}$ represents $\mathrm{SS}$ arrivals that turn above the $410 \mathrm{~km}$ discontinuity, at small distances these arrivals turn within the lithosphere. Branch CD represents arrivals turning within the transition zone from 410 to $660 \mathrm{~km}$ depth. Finally, branch EF corresponds to waves that have turned below the $660 \mathrm{~km}$ discontinuity. 
(A)

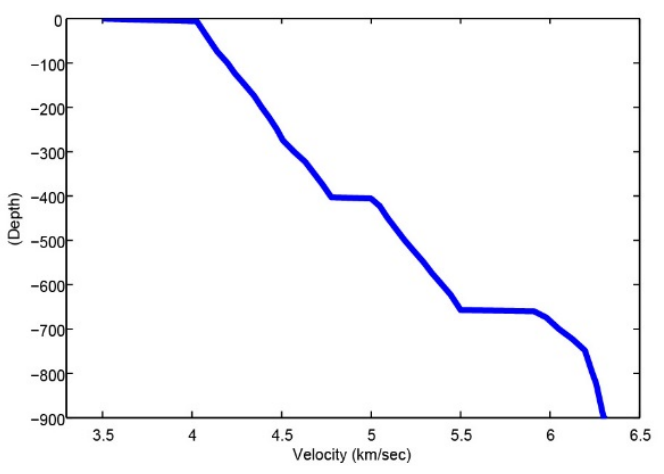

(B)

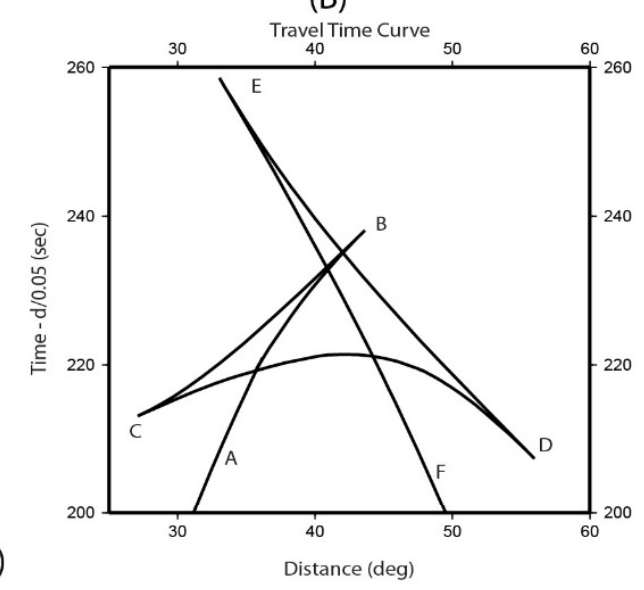

(C)

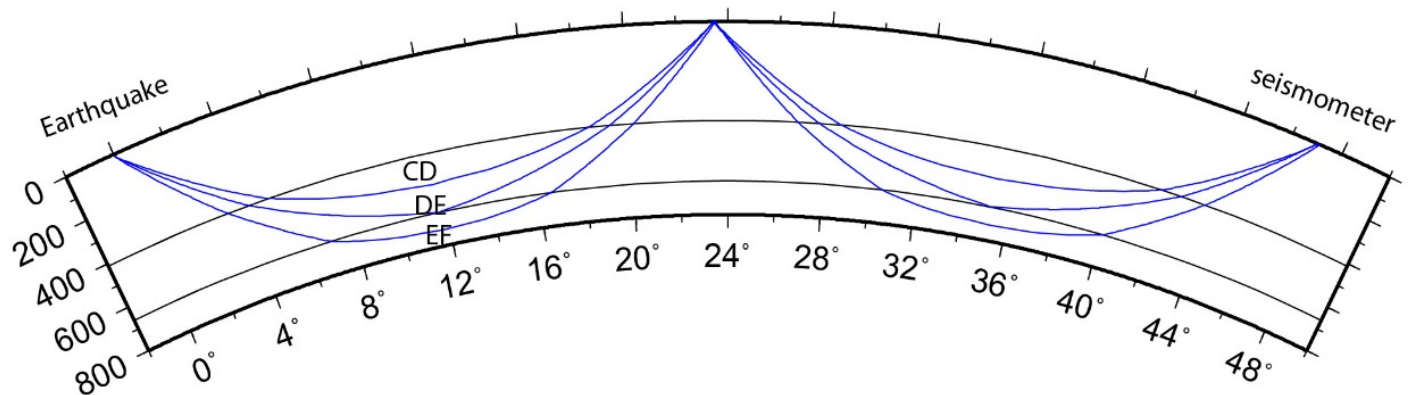

Figure 2. Raypaths and travel time curve for a simple model of shear velocity wih depth. Helmberger (1984) without the high velocity lid. (B) Travel time curve for the SS phase. (C) Ray paths at a distance of $47^{\circ}$. Paths CD and EF sample depths between $410 \mathrm{~km}$ and $660 \mathrm{~km}$, and below the $660 \mathrm{~km}$ discontinuity respectively. The DE is a reflected wave from the $410 \mathrm{~km}$ discontinuity. Letters C, D, E, F in (C) correspond to those in (B).

The time separation and amplitude of different branches with distance is sensitive to the velocity gradient between the discontinuities as well as to the velocity increase across the respective discontinuities. Note that the CD arrivals are rarely first arrivals but over most distances arrive as secondary arrivals. The travel time curve reveals that for SS wave phases, a complete data profile from $30^{\circ}$ to $60^{\circ}$ covers all the triplicated arrivals. Thus, with a data profile over this range, we can constrain the velocity structure of the transition 


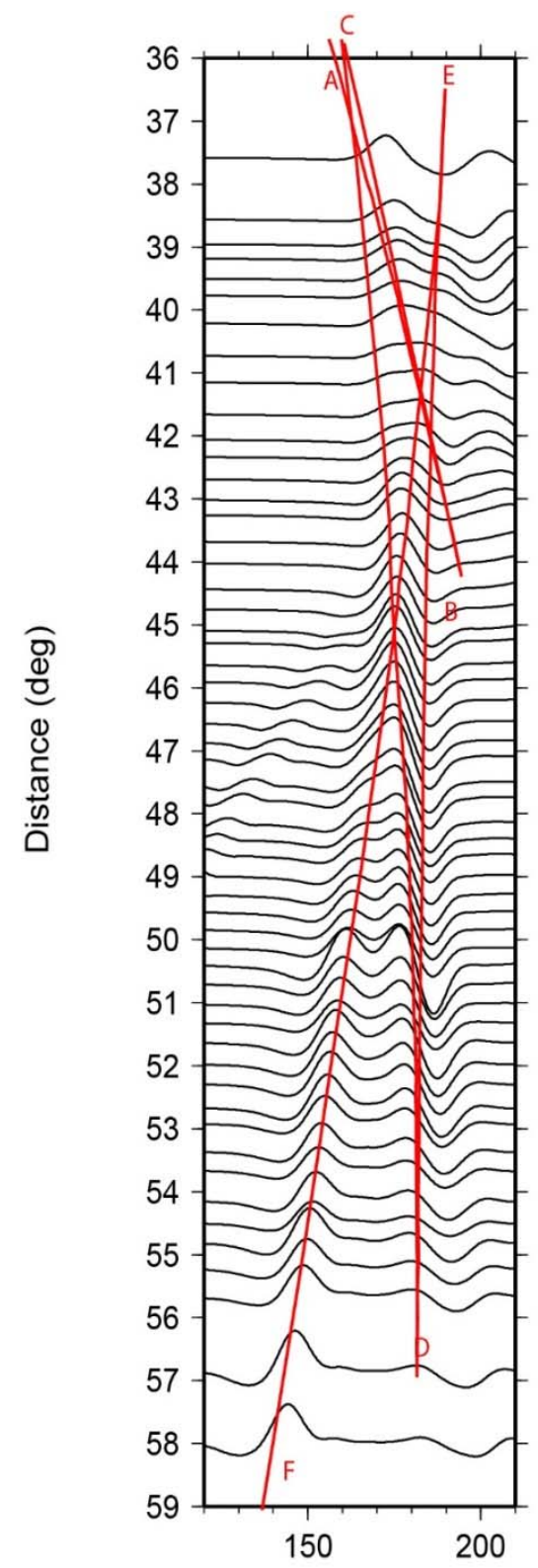

Time after S wave arrival (sec) with reduced velocity 4.5 (sec/deg)

Figure 3. A profile of synthetic seismograms using the TNA model (Grand and Helmberger, 1984) between $35^{\circ}$ and $60^{\circ}$ distance. Red lines present the arrivals shown in the travel time curve, (figure 2B). Letters A, B, C, D, E, F correspond to those in figure 2(B). Note the complex waveforms that change with distance as multiple waves interfere with each other. 
zone. The travel times used to construct common reference models like PREM (Dziewonski and Anderson, 1981) or AK135 (Kennett et al., 1995) consist of first arrival $\mathrm{P}$ and $\mathrm{S}$ turning waves and thus do not include information from many waves most sensitive to the velocity within the transition zone.

Upper mantle turning waves have been used to obtain detailed models of the upper mantle before, but in many cases resolution was limited for a number of reasons. First, most attempts at modeling upper mantle waveforms have used trial and error fitting so that the resolution that these seismic models provide is difficult to assess. Another common problem with past studies using turning waves is that sometimes a 1-D model is extracted from data produced by various earthquakes that actually sample fully three dimensional structures and it has been difficult to assess the effect of these 3-D variations on the models. A third problem is that often the data set used to investigate the upper mantle is limited in distance such that data do not cover the entire distance range over which triplicated arrivals appear. In this study we take advantage of USArray data from the Earthscope project (www.usarray.org) to invert for profiles of shear velocity as a function of depth through the upper mantle. USArray consists of 400 broadband seismic stations that have been sequentially deployed across the United States beginning on the west coast. USArray recordings of SH waves produced by East Pacific earthquakes provide unprecedented profiles of upper mantle triplicated waveforms that span the entire distance range of the transition zone along a single azimuth. We use several dense profiles of seismic data in this study to minimize the effect of three dimensional variations in determining velocity as a function of depth. We also use a waveform inversion technique that utilizes a conjugate gradient algorithm to fit the data. This allows us to more quantitatively estimate resolution in our models. 


\section{Chapter 2: Data and Observation}

We used several earthquakes (see Table 1) on the East Pacific Rise recorded by US-Array stations in the western United States as well as Canadian network stations in western Canada to produce three models of upper mantle shear velocity as a function of depth. The data span $30^{\circ}$ to $60^{\circ}$ in distance and thus SS waves sample the upper mantle turning at depth from 150 to $800 \mathrm{~km}$ including triplicated arrivals from both the 410 and $660 \mathrm{~km}$ discontinuities. Figure 4 shows the earthquakes used as well as the seismic stations and midpoints of the SS waves. The stations and midpoints are color coded showing the data profiles used to develop three upper mantle models. We used SS waves in this study due to the high quality of data produced by multiple earthquakes on the same fracture zone in the East Pacific Rise that allowed us to simultaneously examine several profiles of data as US-Array migrated across the United States (figure 4). Transition zone heterogeneity has been imaged in the western United States (Schmandt and Humphries, 2010). Examining three different profiles allows us to estimate the effect of lateral variations on vertical profiles of velocity. SS waves are also somewhat easier to use than $\mathrm{S}$ waves for upper mantle modeling in that travel times and amplitudes can be determined relative to the observed $\mathrm{S}$ waves which minimizes uncertainty in earthquake origin time as well as crustal and shallow mantle heterogeneity beneath stations. The SS data we use here all bounce beneath relatively young oceanic crust and thus there is likely little local variation in crustal thickness beneath the bounce points. To minimize noise, we stacked the data for a single earthquake within .25 degrees distance bins (Figure 4). Finally, the data were bandpass filtered between .01 and $.07 \mathrm{~Hz}$. 


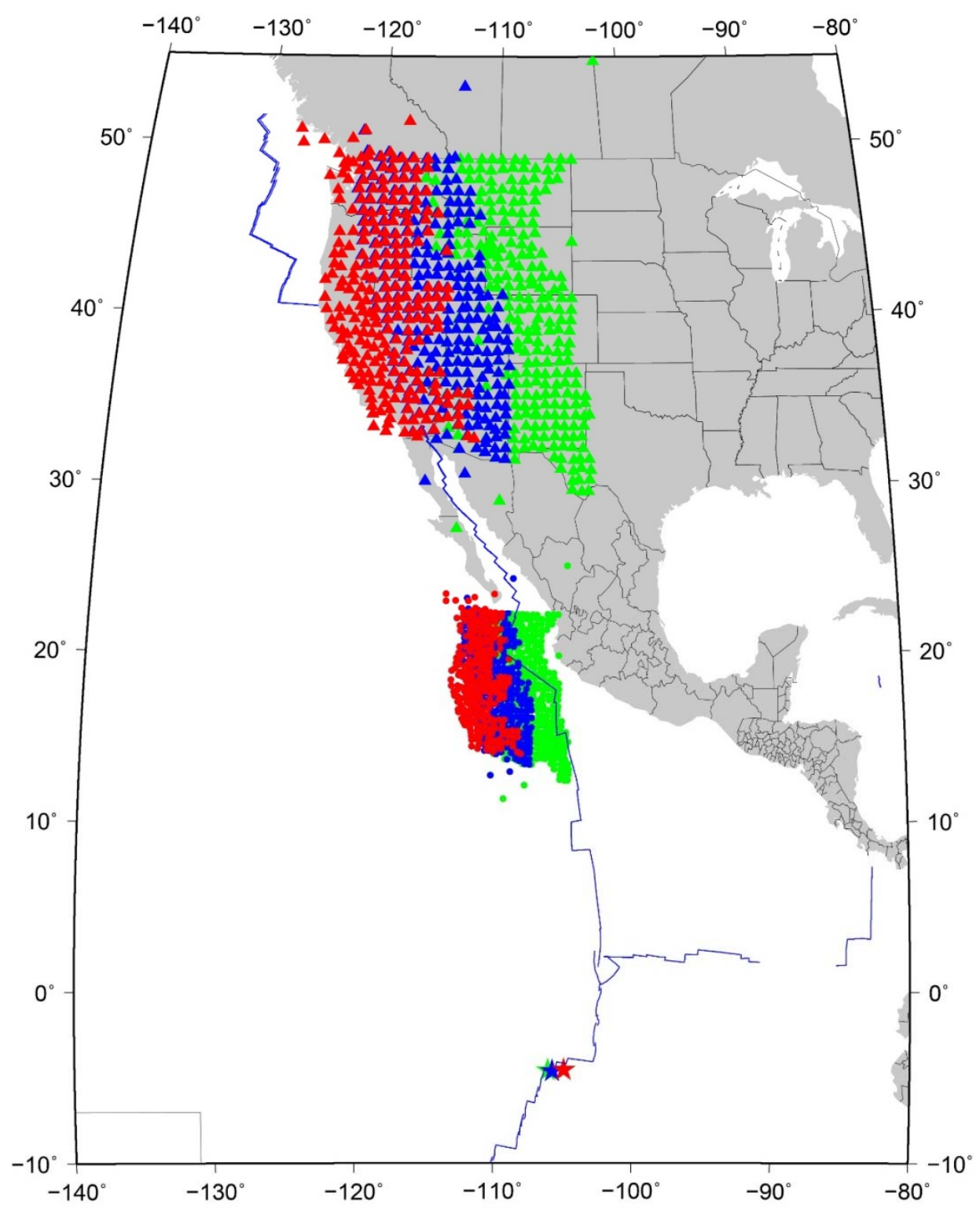

Figure 4. Location of stations (triangles), earthquakes (stars) and the midpoints (dots) between stations and the earthquakes for the data inverted for seismic structure. The color code corresponds to the different earthquake sources, red for earthquake A, blue for earthquake B, and green for earthquake $\mathrm{C}$ (table 1). In some cases the same stations were used for two events but in general the three events sample three different profiles from west to east. 
Grand and Helmberger (1984) modeled data along paths similar to what we analyze here, however, in that study few seismic stations were used such that the model (TNA) was produced by combining paths over a range of azimuths that sampled several different tectonic domains within North America. Furthermore, the model was derived by trial and error modeling and does not, in fact, produce good fits to all data shown in that work.

Figure 5a shows a profile of SS data for earthquake A (Table 1) compared to synthetics computed for the TNA model. The $\mathrm{S}$ waves of synthetics and data are aligned although the $\mathrm{S}$ waves are not shown in the figure. We used a depth of $8 \mathrm{~km}$ as an average crustal thickness in the synthetics. Maximum SS-S travel time shifts, caused by errors in crustal thickness, are less than $1 \mathrm{sec}$ for reasonable variations in ocean crustal thickness as well as the fact that the crust beneath the stations is continental. The synthetics were computed using the reflectivity technique of Fuchs and Mueller, (1971). In both data and synthetics, multiple arrivals are observed, however the SS timing is off from $40^{\circ}$ to $45^{\circ}$ distance and although the first pulse in SS beyond $47^{\circ}$ distance is matched well, the second arrival is not. Figure $5 \mathrm{~b}$ shows the comparison of the same data with synthetics computed using a modified PREM model. To take into account the shallow slow shear velocities beneath the East Pacific Rise, we modified the upper 300km depth of the PREM model using TNA since to first order TNA fits the timing of the data. The travel times of the first arrivals in the SS waves are well fit beyond $47^{\circ}$ distance, but, again, there is a poor match for the second arrivals. As discussed above, the second arrivals at these distances are those that turn within the transition zone and are thus most sensitive to transition zone structure. Figure $5 \mathrm{c}$ shows a comparison of data and synthetics computed using a modified AK135 model. This model also does not produce an acceptable fit for the observed waveforms. 
(A)

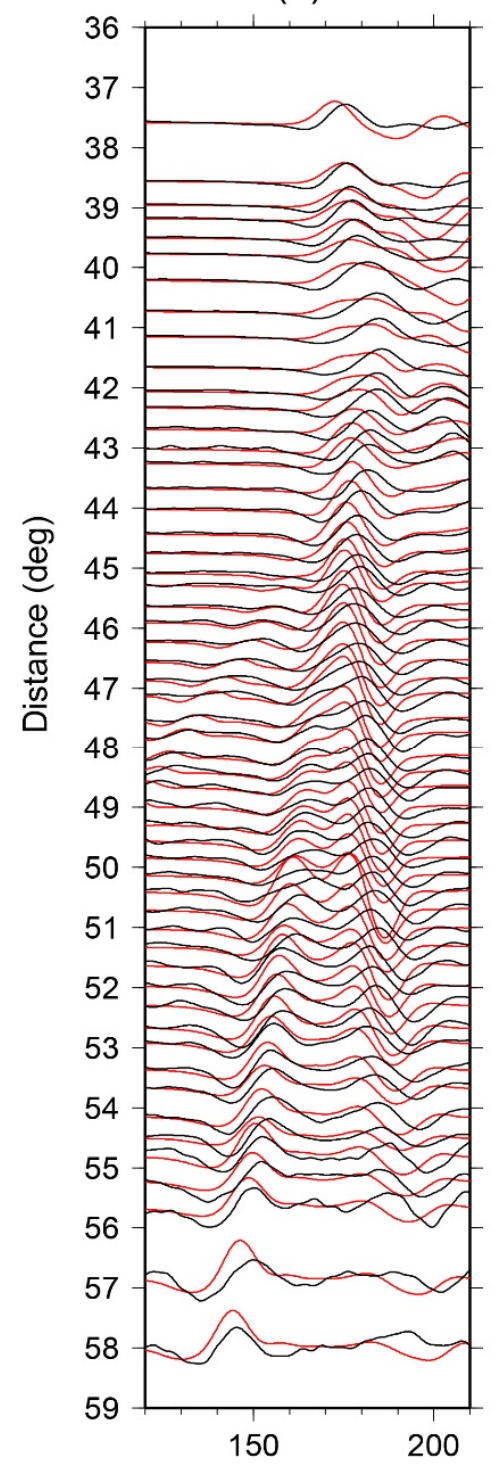

(B)

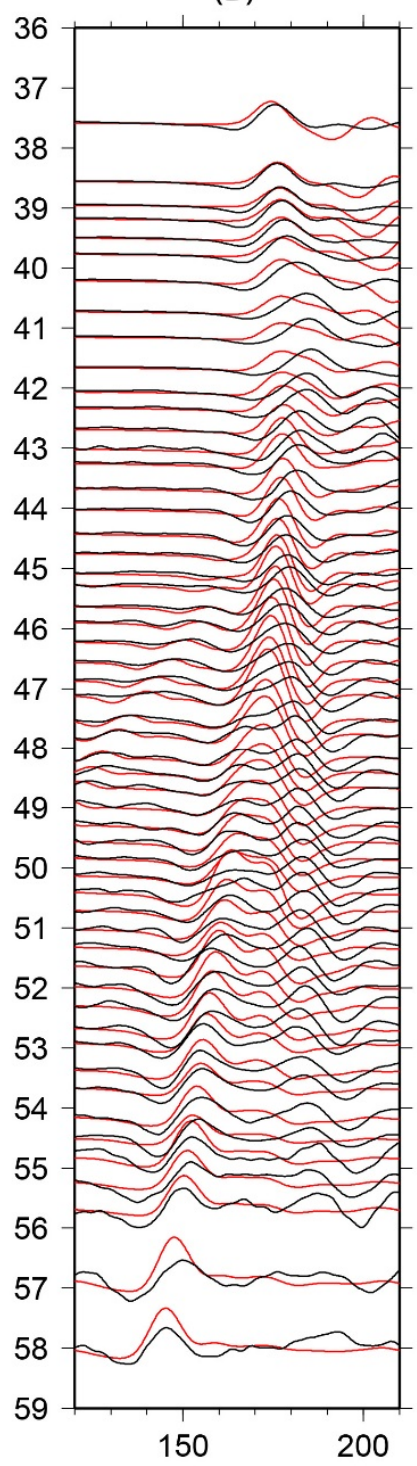

(C)

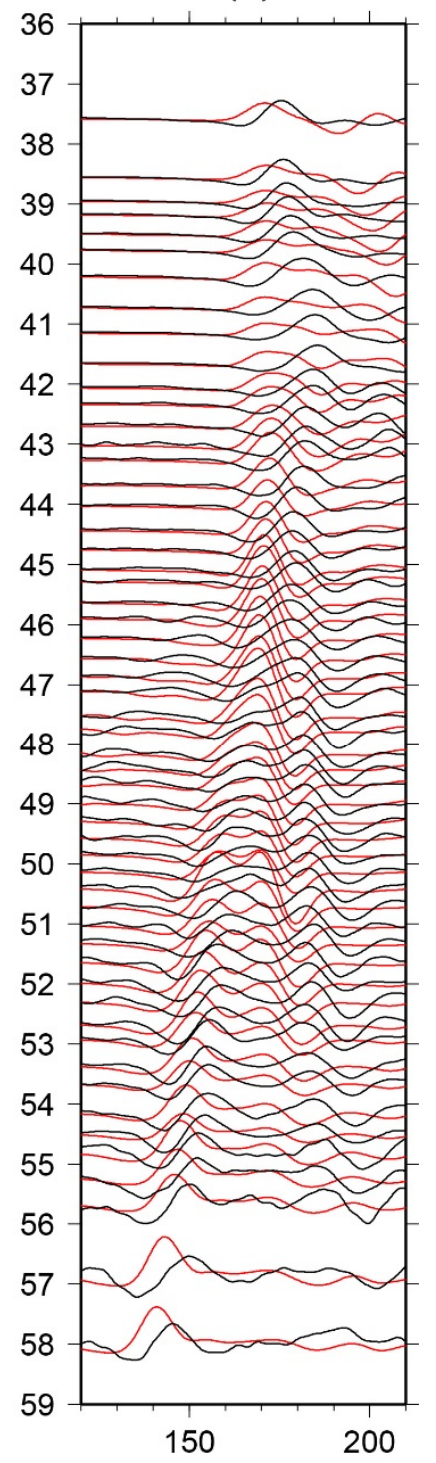

Time after S wave arrival (sec) with reduced velocity 4 (sec/deg)

Figure 5. Comparison of seismic data (black traces) from earthquake A with synthetic seismograms (red traces) computed using model TNA (A), the PREM model (B), and the AK135 model (C). All three models have the upper $300 \mathrm{~km}$ replaced by the shear velocities in model TNA. 


\section{Chapter 3: Methods}

To determine the seismic shear velocity structure of the transition zone beneath the East Pacific Rise, we used a linearized waveform inversion technique. The algorithm we use was originally applied to seismology by Mora (1988), and later applied by Matzel and Grand, (2004) and Gao et al., (2006) to upper mantle seismic waveforms recorded in East Europe and North America respectively. The details of the algorithm are given in Matzel, (2002).

We briefly review the approach here. The general nonlinear forward model for a seismic waveform synthetic can be written as:

$$
\mathbf{d}=\mathrm{f}\left(\mathbf{m}, \mathrm{r}_{\text {inst }}, \mathrm{r}_{\text {source }}\right)
$$

Where $\mathbf{d}$ is the seismic data, $\mathbf{m}$ is an Earth model vector, and $\mathrm{f}$ is a nonlinear operator that maps the model space $M$ into the data space $D$, and $r_{\text {inst }}$ and $r_{\text {source }}$ are instrument response and source information (mechanism and time function), respectively. Our objective is to find a model $\mathbf{m}$ that best fits the seismic observations by minimizing the difference between synthetic and observed waveforms. To linearize the nonlinear problem, we can write the relation:

$\Delta \mathbf{d}=\left[\frac{\partial \mathrm{f}}{\partial \mathrm{m}}\right] \Delta \mathbf{m}=\mathrm{D} \Delta \mathbf{m}$

where $\Delta \mathbf{d}=\mathbf{d}-\mathbf{d}_{\mathbf{o b s}}$ is the difference between data and synthetics, and $\Delta \mathbf{m}=\mathbf{m}-$ $\mathbf{m}_{0}$ is the difference between the starting model and the real model of the Earth. The term $D=[\partial \mathrm{f} / \partial \mathbf{m}]$ is a matrix of differential seismograms which is a measurement of the sensitivity of the seismograms to perturbations in $\mathbf{m}$. We used the reflectivity method [Fuchs and Muller, 1971] to generate the synthetics and the differential seismograms. The solution of equation (3) depends on the starting model due to the nonlinear nature of the 
original problem. To solve equation (3), the conjugate gradient algorithm iteratively minimizes the misfit function:

$\mathrm{S}(\mathbf{d}, \mathbf{m})=1 / 2\left[\Delta \mathbf{d}^{\mathrm{T}} \mathrm{C}_{\mathrm{d}}^{-1} \Delta \mathbf{d}+\Delta \mathbf{m}^{\mathrm{T}} \mathrm{C}_{\mathrm{m}}^{-1} \Delta \mathbf{m}\right]$

Where $C_{d}$ and $C_{m}$ are the covariance matrices for data and model spaces, respectively ( $\mathrm{T}$ indicates conjugate transpose). The algorithm for nonlinear least squares using preconditioned conjugate gradients is given by:

$\mathbf{g}_{\mathrm{n}}=\frac{\partial \mathrm{S}(\mathbf{d}, \mathbf{m})}{\partial \mathbf{m}}=\mathrm{D}_{\mathbf{n}}^{\mathbf{T}} \mathrm{C}_{\mathrm{d}}^{-1} \Delta \mathbf{d}_{\mathrm{n}}+\mathrm{C}_{\mathbf{m}}^{-1} \Delta \mathbf{m}_{\mathrm{n}}$

$\mathbf{c}_{\mathrm{n}}=\mathbf{p}_{\mathrm{n}}+\frac{\mathbf{p}_{\mathrm{n}}^{\mathrm{T}}\left(\mathbf{g}_{\mathrm{n}}-\mathbf{g}_{\mathrm{n}-1}\right)}{\mathbf{p}_{\mathrm{n}}^{\mathrm{T}} \mathbf{g}_{\mathrm{n}}} \mathbf{c}_{\mathrm{n}-1} \quad \mathbf{c}_{1}=\mathbf{p}_{1}, \mathrm{pn}=\mathrm{C}_{\mathrm{m}} \mathbf{g}_{\mathrm{n}}$

$\eta_{\mathrm{n}}=\frac{\mathbf{c}_{\mathrm{n}}^{\mathrm{T}} \mathbf{g}_{\mathrm{n}}}{\mathbf{c}_{\mathrm{n}}^{\mathrm{T}} \mathrm{D}_{\mathrm{n}}^{\mathrm{T}} \mathrm{C}_{\mathrm{d}}^{-1} \mathrm{D}_{\mathrm{n}} \mathbf{c}_{\mathrm{n}}+\mathbf{c}_{\mathrm{n}}^{\mathrm{T}} \mathrm{C}_{\mathrm{m}}^{-1} \mathbf{c}_{\mathrm{n}}}$

$\mathbf{m}_{\mathrm{n}+1}=\mathbf{m}_{\mathrm{n}}-\eta_{\mathrm{n}} \mathbf{c}_{\mathrm{n}}$

Where $\mathrm{n}$ is the iteration number, $\mathbf{g}_{\mathrm{n}}$ is the gradient of the misfit function which is also $1 / 2$ the direction of steepest descent, $\mathbf{p}_{\mathrm{n}}$ is a preconditioned gradient, $\mathbf{c}_{\mathrm{n}}$ is the conjugate direction vector, $\eta_{\mathrm{n}}$ is the step length. The model $\mathbf{m}_{\mathrm{n}}$ is updated by $\eta_{\mathrm{n}}$ along the conjugate direction $\mathbf{c}_{\mathrm{n}}$, with $\mathbf{m}_{\mathrm{n}+1}$ the updated model. The conjugate gradient algorithm converges rapidly for upper mantle waveform problems (Matzel, 2002] and it iteratively minimizes the difference between data and synthetics in a least squares sense to find the local best fitting model. The inversion algorithm overcomes the deficiency of the trial-and-error modeling by producing an optimal data fit with some a-priori constraints and can also be used to get uncertainty estimates for the models.

A difficulty with linearized waveform inversion is that if the starting model predicts synthetics that are more than $1 / 2$ cycle different than the data the inversion can converge to a wrong model predicting synthetics one cycle off from the data. The conjugate gradient 
method will find the closest local minima and thus inversion results depend on the starting model. We used model TNA to start our inversion as this model fits travel times to first order across the distance range. Then we derive a top-down solution where the data most sensitive to the crust and shallow mantle is fit first and then the deeper mantle structure is solved for. We also begin with longer period filters and then progressively model broader band data. This results in a starting model for the deeper mantle structure that has better alignment of arrivals that reduces the cycle skipping problem. We accomplish this by selecting time windows of whole SS waveforms for successive inversions where an intermediate result is the input for the next run. Once the misfit doesn't change any more we stop the inversion and get the final model. 


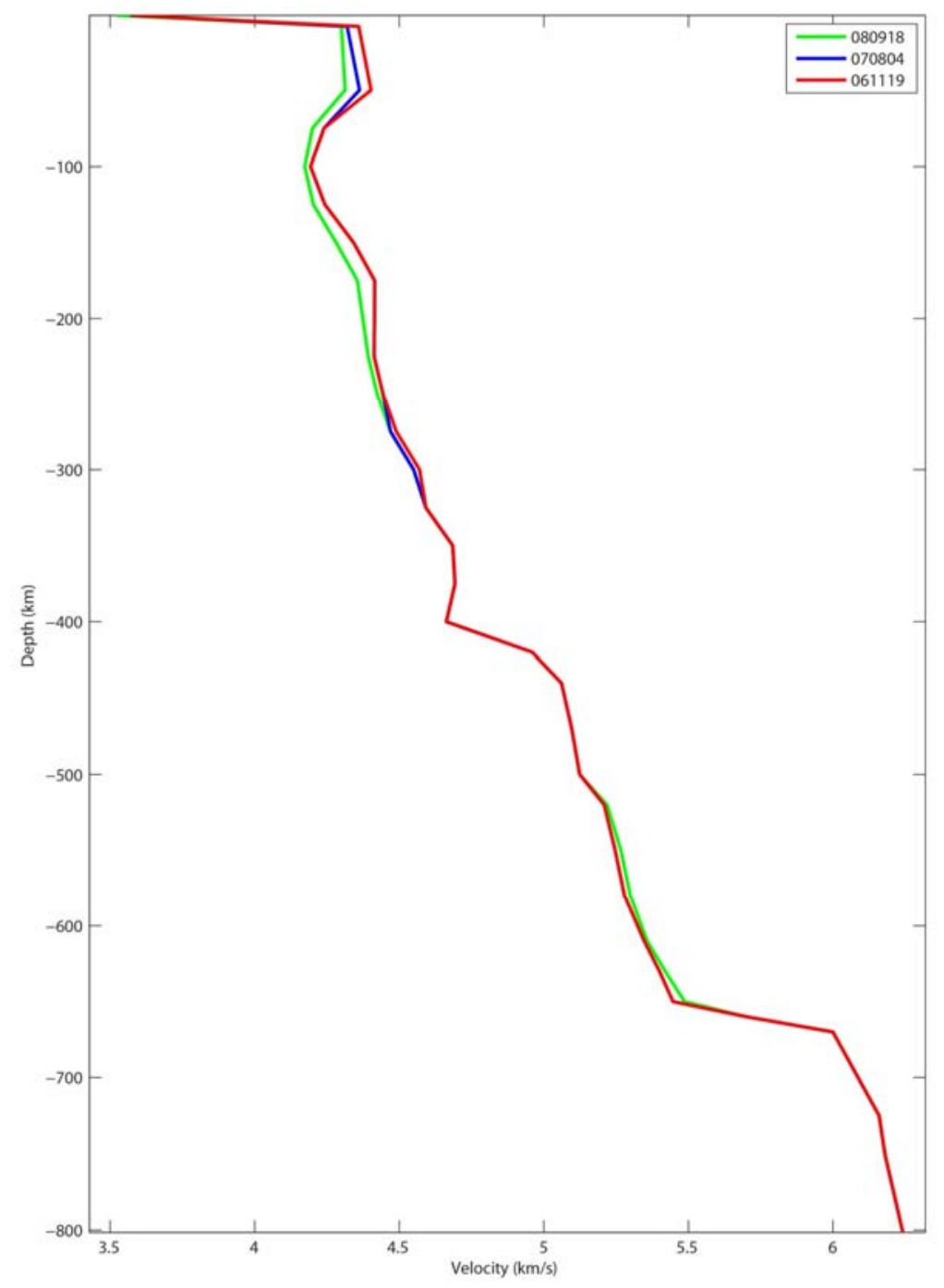

Figure 6. Inversion results for shear velocity as a function of depth using data from earthquakes A (red line), B (blue line), and C (green line). The three models were derived by independent inversions. 


\section{Chapter 4: Results}

The model results from inverting data from three separate profiles corresponding to earthquakes $\mathrm{A}, \mathrm{B}$, and $\mathrm{C}$ are shown in figure 6 . The models differ by up to $.8 \%$ in the shallow mantle but are very similar within the transition zone. The mid-points for the three data profiles range from the East Pacific Rise crest to roughly $8 \mathrm{Ma}$ crust to the west of the ridge. Earthquake $\mathrm{C}$ was the source for the furthest east profile and also produced the slowest model implying slower shallow mantle velocity beneath the ridge as one would expect. The significance of the similarity of the models in the transition zone is that they sample different parts of western North America where transition zone lateral heterogeneity has been previously imaged (e.g. Schmandt and Humphreys, 2010). The similarity of our results shows that the short wavelength heterogeneities beneath western North America are not significant in terms of average shear velocity as a function of depth.

The comparisons of data to synthetics for the three velocity models are presented in figure 7. The fits of the synthetics to the data for all three profiles are excellent except at the closest distances where the SS waves are mostly sensitive to velocities in the shallow mantle (figure 2). It is noteworthy, however, that the timing and waveforms are well fit from $40^{\circ}$ to up to $60^{\circ}$ distance which spans the full distance range over which transition zone turning waves arrive. If one compares figure 7 to figure 5 the improvement in data fit for the new models over the three reference models discussed above is obvious. Due to the similarity of the three models in the transition zone we average them to produce a single model that we call TNA2. The model is given in table 2. 
(A)

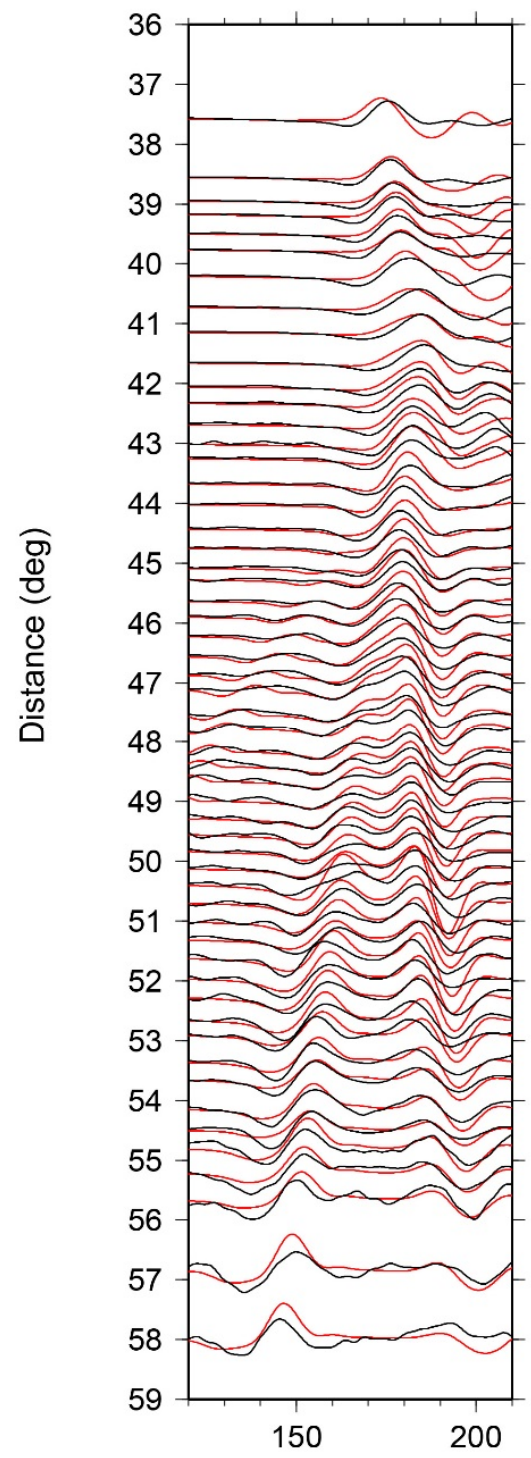

(B)

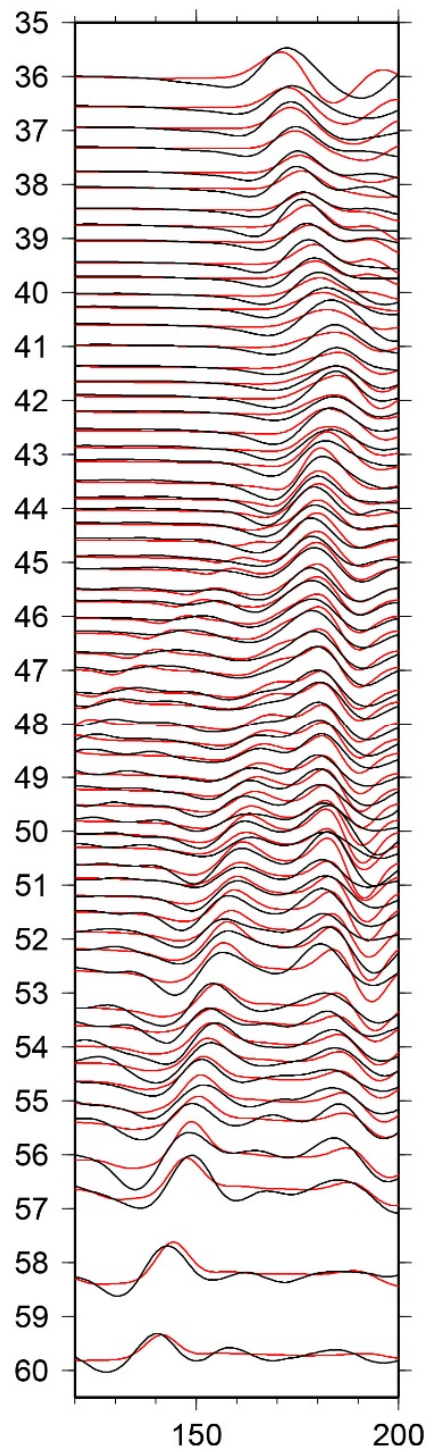

(C)

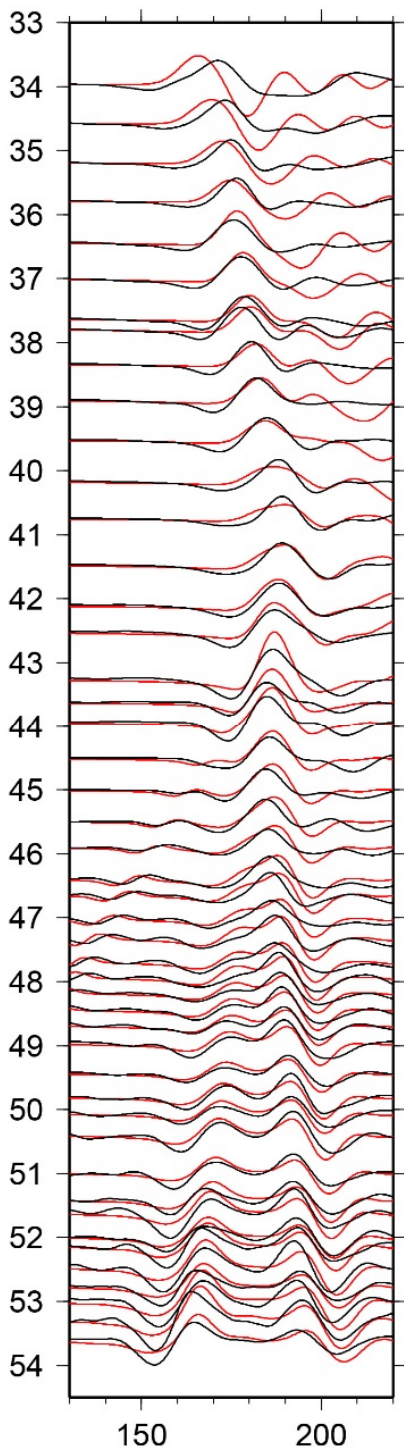

Time after S wave arrival (sec) with reduced velocity (A) 4, (B) 4.6, (C) 4 (sec/deg)

Figure 7. Comparison of data from profiles produced by earthquakes $\mathrm{A}, \mathrm{B}$, and $\mathrm{C}$ to synthetic seismograms (red traces) computed using the inversion results from figure 6 . 


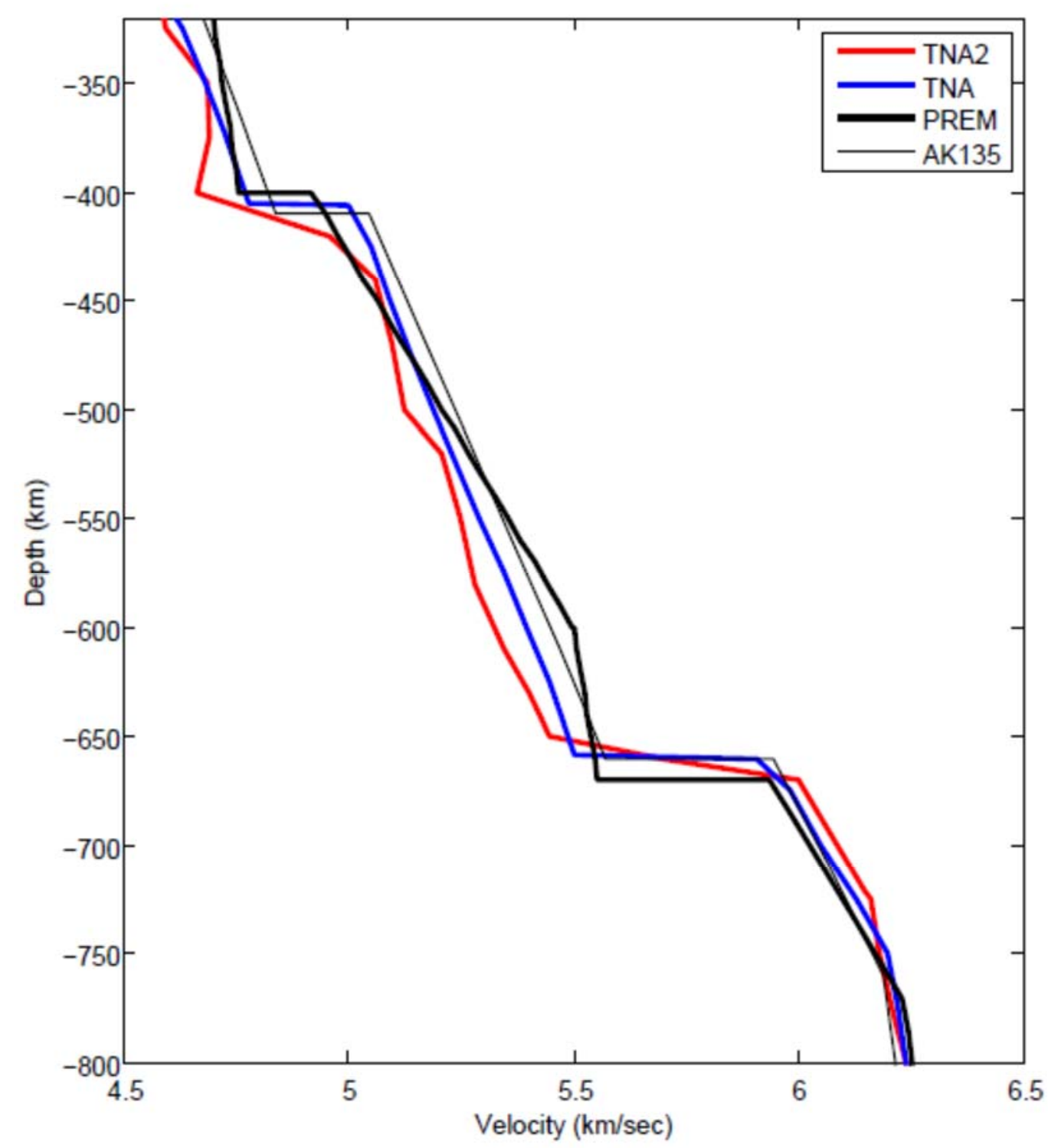

Figure 8. Comparison between the TNA2 model (red line) and previously published models of transition zone shear velocity as a function of depth. The thick black line is the PREM model, the thin black line the AK135 model, and the blue line is TNA model.

Figure 8 compares the TNA2 model with the TNA model (Grand and Helmberger, 1984), the PREM model (Dziewonski and Anderson, 1981), and the AK135 model (Kennett et al., 1995). TNA2 has larger jumps in velocity across the $410 \mathrm{~km}$ and $660 \mathrm{~km}$ depth 
discontinuities than the other models do. Here, we take the total velocity increase over a $50 \mathrm{~km}$ depth interval to define the discontinuity size, from $385 \mathrm{~km}$ to $435 \mathrm{~km}$ for the 410 $\mathrm{km}$ discontinuity and from $635 \mathrm{~km}$ to $685 \mathrm{~km}$ for the $660 \mathrm{~km}$ discontinuity. We do this because the turning wave data we use here only have a depth resolution of roughly 50 $\mathrm{km}$. In TNA2, we find an increase of $7.1 \%$ for the shear wave velocity increase corresponding to the $410 \mathrm{~km}$ discontinuity and an increase of $10.5 \%$ across the $660 \mathrm{~km}$ discontinuity, while PREM has an increase of $5.5 \%$ across the $410 \mathrm{~km}$ discontinuity and an increase of $7.6 \%$ across the $660 \mathrm{~km}$ discontinuity. Model AK135 has a $6.3 \%$ velocity increase across the $410 \mathrm{~km}$ depth discontinuity and an $8.0 \%$ velocity increase across the $660 \mathrm{~km}$ depth discontinuity. The larger discontinuities in TNA2 are accompanied by an overall lower transition zone gradient as can be seen in figure 8 . The result of this lower gradient is that TNA2 has slower shear velocities from $550 \mathrm{~km}$ to $650 \mathrm{~km}$ depth than the seismic models discussed above.

Other features of the TNA2 model that should be noted are smoother jumps in velocity across the discontinuities than are found in the other models discussed above as well as a low velocity zone $50 \mathrm{~km}$ above the $410 \mathrm{~km}$ discontinuity. We discuss these features below. 
(A)

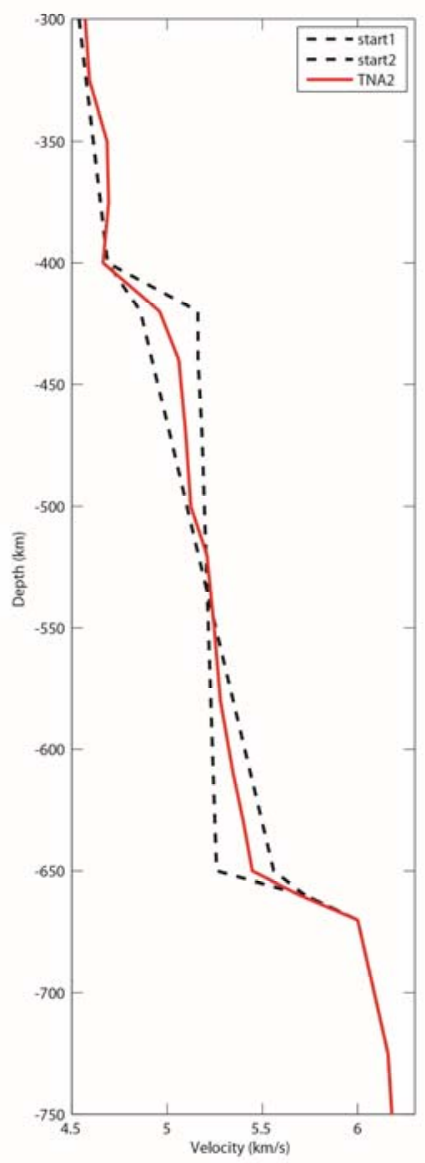

(B)

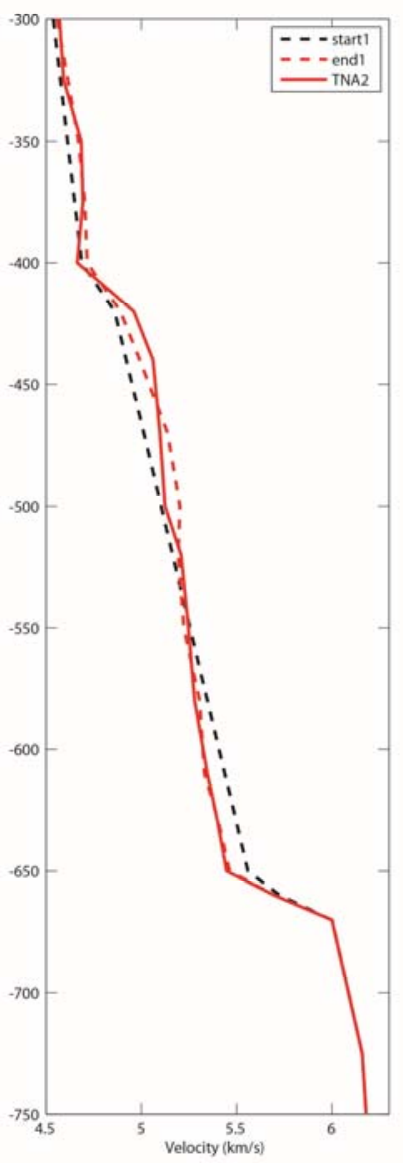

(C)

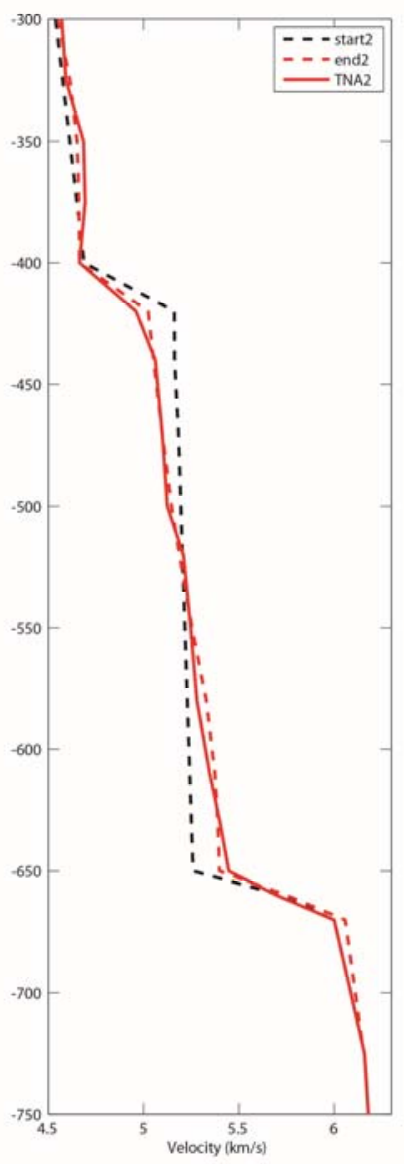

Figure 9. Starting models used to test resolution. The red line in each figure is model TNA2. (A) Two starting models (black dashed lines) used in inversion tests using data from earthquake A. (B) Comparison between model TNA2 (red line) with the high gradient starting model (black dashed line) and the results of inversion using the black dashed model as a starting model (red dashed line). (C) Comparison of model TNA2 (red line) with the low gradient starting model (black dashed line) and the results of the inversion (red dashed line). 


\section{Chapter 5: Resolution Test}

The conjugate gradient inversion results depend on the starting model as it is possible for the inversion to find local minima and not the true best fitting model. To test the uniqueness of our results, we run the inversion for a range of different starting models focusing primarily on the velocity gradient in the transition zone and the size of the velocity jumps at $410 \mathrm{~km}$ and $660 \mathrm{~km}$ depth.

We test two starting models with transition zone gradients that differ from TNA2 (figure 9a). For one model we start with a higher transition zone gradient than TNA2 and smaller velocity jumps across the discontinuities. The other starting model has larger discontinuities and a lower gradient than TNA2. Figures 9 b,c show the models that result from inverting the data using the two respective starting models compared to TNA2. Figure $9 \mathrm{c}$ shows that starting the inversion with larger discontinuities and a lower gradient within the transition zone results in a model almost identical to TNA2. The model that results from using a starting model with smaller discontinuity size and a higher gradient is less similar to TNA2 (figure 9b) however the differences are still small. In this case the difference is due to an oscillation in the test model with respect to TNA2 over a $100 \mathrm{~km}$ depth interval with the average velocity over that depth range the same between the two models i.e. one model is a little faster than the other over a $50 \mathrm{~km}$ depth interval and then slower for the next $50 \mathrm{~km}$ depth interval. Still, the average gradient within the transition zone between the two models is nearly the same and the jump in velocity across the $410 \mathrm{~km}$ discontinuity is similar if one allows for the jump to occur over about $70 \mathrm{~km}$ depth. The wavelengths of the SS waves we use are close to $100 \mathrm{~km}$ so that it is not surprising that resolution over $50 \mathrm{~km}$ depth intervals is limited. Figures 10 and 11 show comparisons between the data and synthetics made from using the two starting models as well as comparisons after inversion. Note the waveform misfit using the starting models. The synthetic to data fit after inversion for both tests is similar to that between the data and the synthetics using the TNA2 model shown in figure $7 \mathrm{a}$. 
(A)

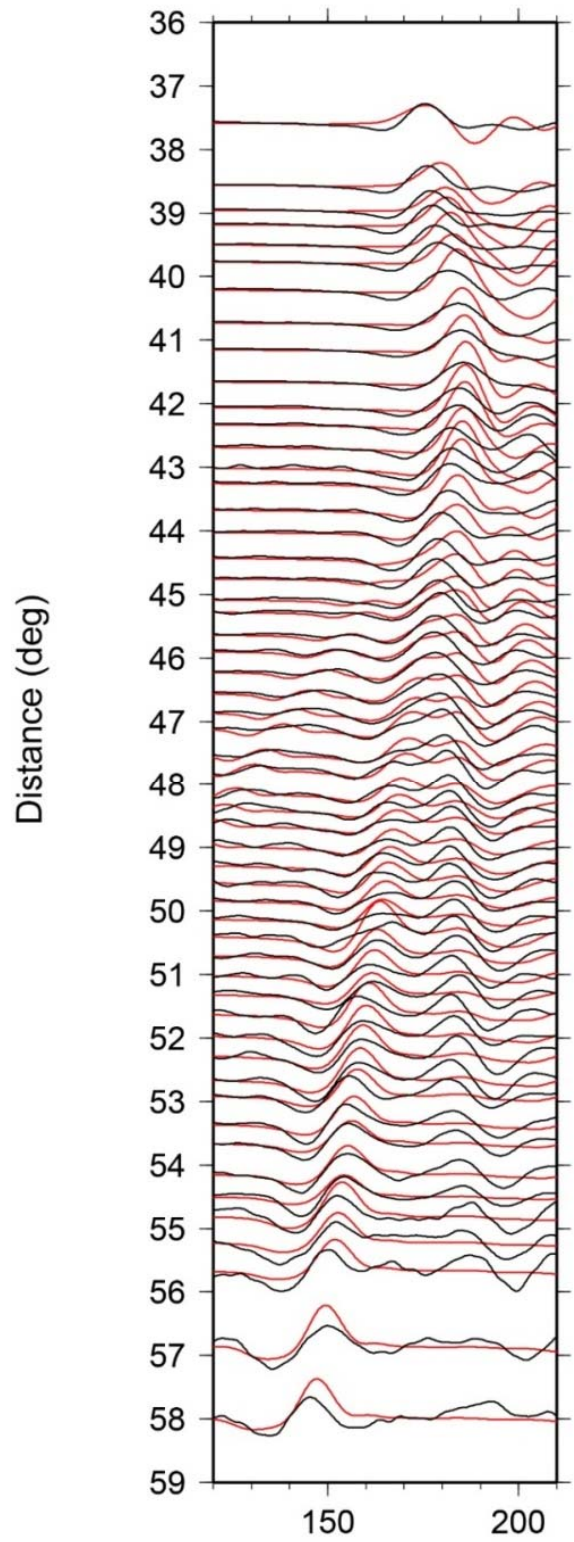

(B)

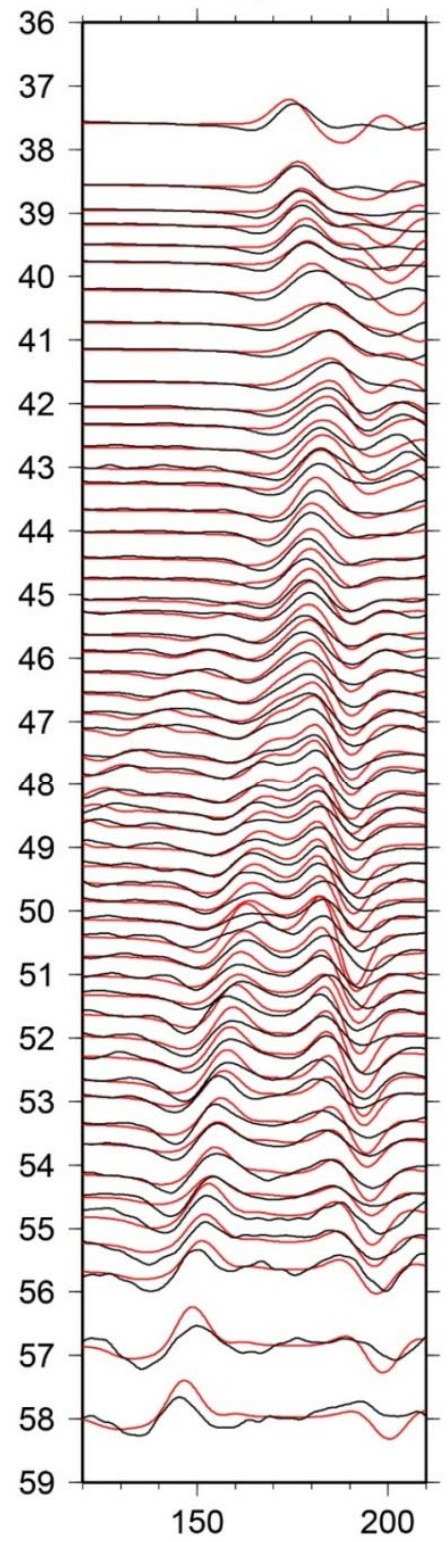

Time after S wave arrival (sec) with reduced velocity 4 (sec/deg)

Figure 10. (A) Comparison of observed tangential seismograms (black traces) and synthetic seismograms (red traces) using the high gradient starting model shown in figure 9B to compute the synthetics. (B) Comparison of observed tangential seismograms (black traces) and synthetic seismograms (red traces) calculated from the model resulting from the inversion using the high gradient starting model shown in figure 9B. 
(A)

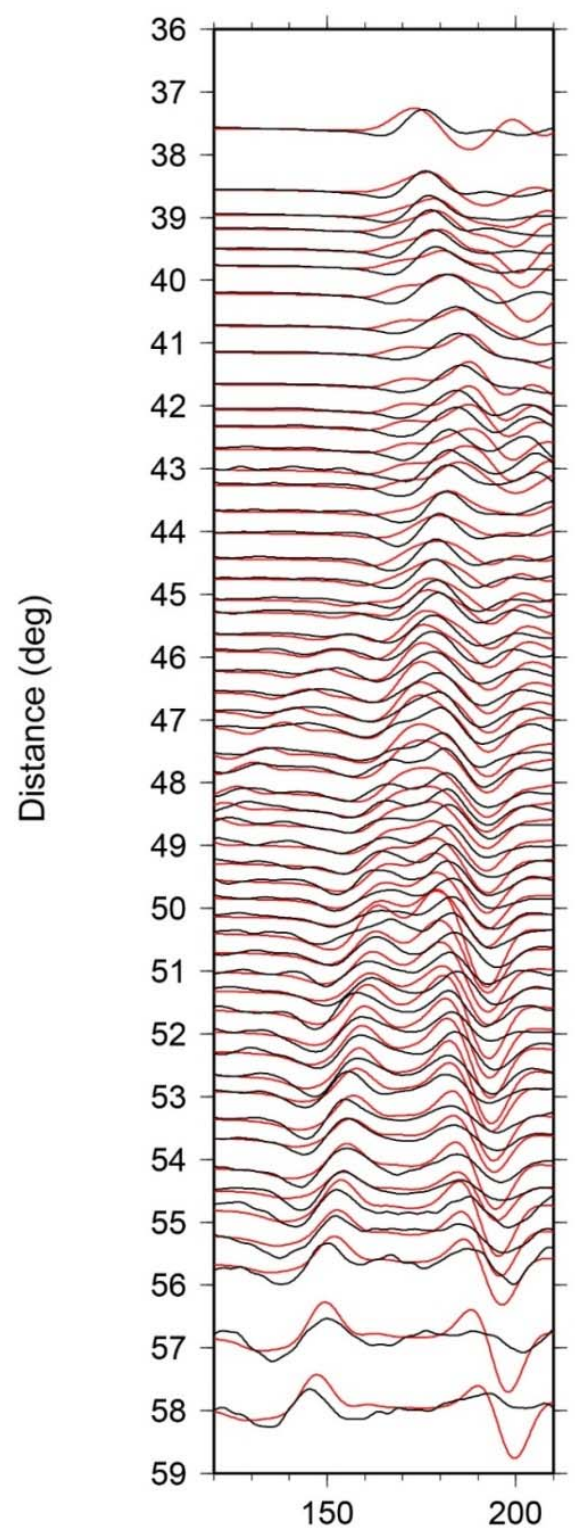

(B)

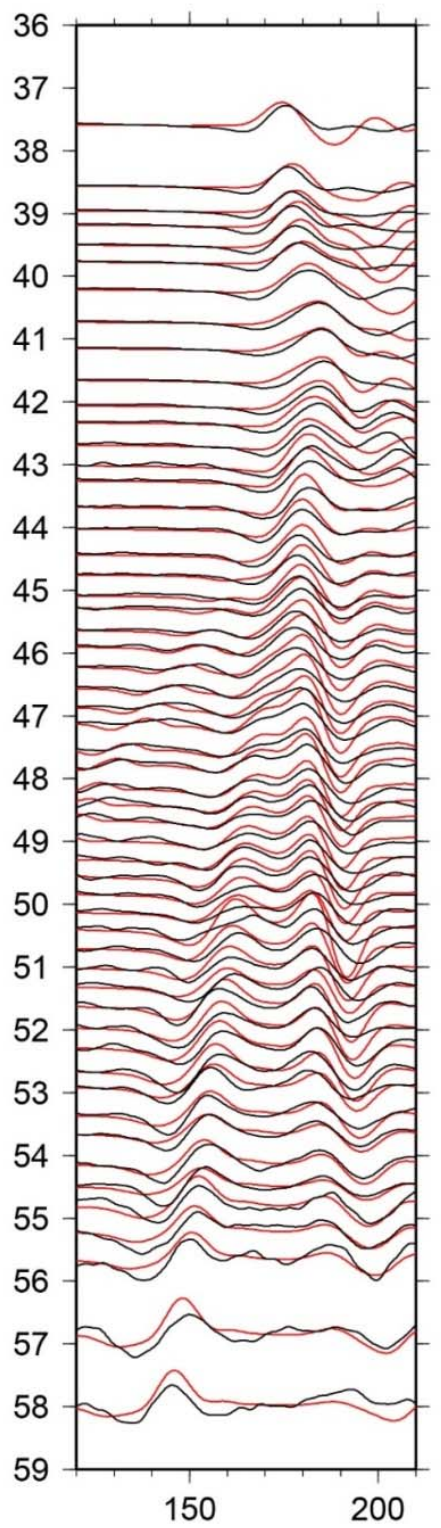

Time after S wave arrival (sec) with reduced velocity 4 (sec/deg)

Figure 11. (A) Comparison of observed tangential seismograms (black traces) and synthetic seismograms (red traces) using the low gradient starting model shown in figure 9C to compute the synthetics. (B) Comparison of observed tangential seismograms (black traces) and synthetic seismograms (red traces) calculated from the model resulting from inversion using the low gradient starting model shown in figure 9C. 
Further tests of resolution are shown in figure 12 where we kept the transition zone gradients in two starting models the same as TNA2 but decreased the size of the $410 \mathrm{~km}$ discontinuity in one case and increased it in the other test. The results of running the inversion for these two starting models are shown in figures $12 \mathrm{~b}$ and $12 \mathrm{c}$. The results of these two inversions again are models very similar to the TNA2 model. We conclude the relatively low gradient and large discontinuity sizes in TNA2 are well resolved by the data, however, the results of our testing also show that resolution is limited to $50 \mathrm{~km}-60$ $\mathrm{km}$ in depth. This obviously means there is little to no resolution of the sharpness of the upper mantle discontinuities.

Model TNA2 has a low velocity zone between $350 \mathrm{~km}$ and $410 \mathrm{~km}$ depth, at the limit of our resolution. The starting model in the inversion for TNA2 has a linear gradient between $200 \mathrm{~km}$ and $400 \mathrm{~km}$ depth. Our inversion used the TNA model as a starting model. Note that there is significant mismatch between data and synthetics at distances from $37^{\circ}$ to $40^{\circ}$ using the TNA model and that the TNA2 model provides much better fits to the data at these distances (figure 5a and figure 7a). We ran our inversion with different starting gradients from 200 to $400 \mathrm{~km}$ depth and found that the best fitting models share a similar negative gradient over $50 \mathrm{~km}$ depth above the $410 \mathrm{~km}$ discontinuity. We also see the same low velocity zone inverting all three data profiles (figure 4 and figure 6). Thus we conclude that the $50 \mathrm{~km}$ low velocity zone atop the $410 \mathrm{~km}$ discontinuity is likely a real feature of the upper mantle averaged beneath the East Pacific Rise and western North America. A low velocity zone above the $410 \mathrm{~km}$ discontinuity was first observed by Revenaugh and Sipkin, (1994) beneath northeast China and then subsequently in different places in the western United States (Song et al., 2004; Gao et al., 2006; Jasbinse et al., 2010). These regions have all been the site of subduction in the past $50 \mathrm{Ma}$ or so. It is not clear if we are sampling this feature solely beneath the western United States or if it also exists beneath the East Pacific Rise as our 
data sample both equally. More detailed analysis of the East Pacific is needed to determine if the structure exists away from a region associated with subduction.
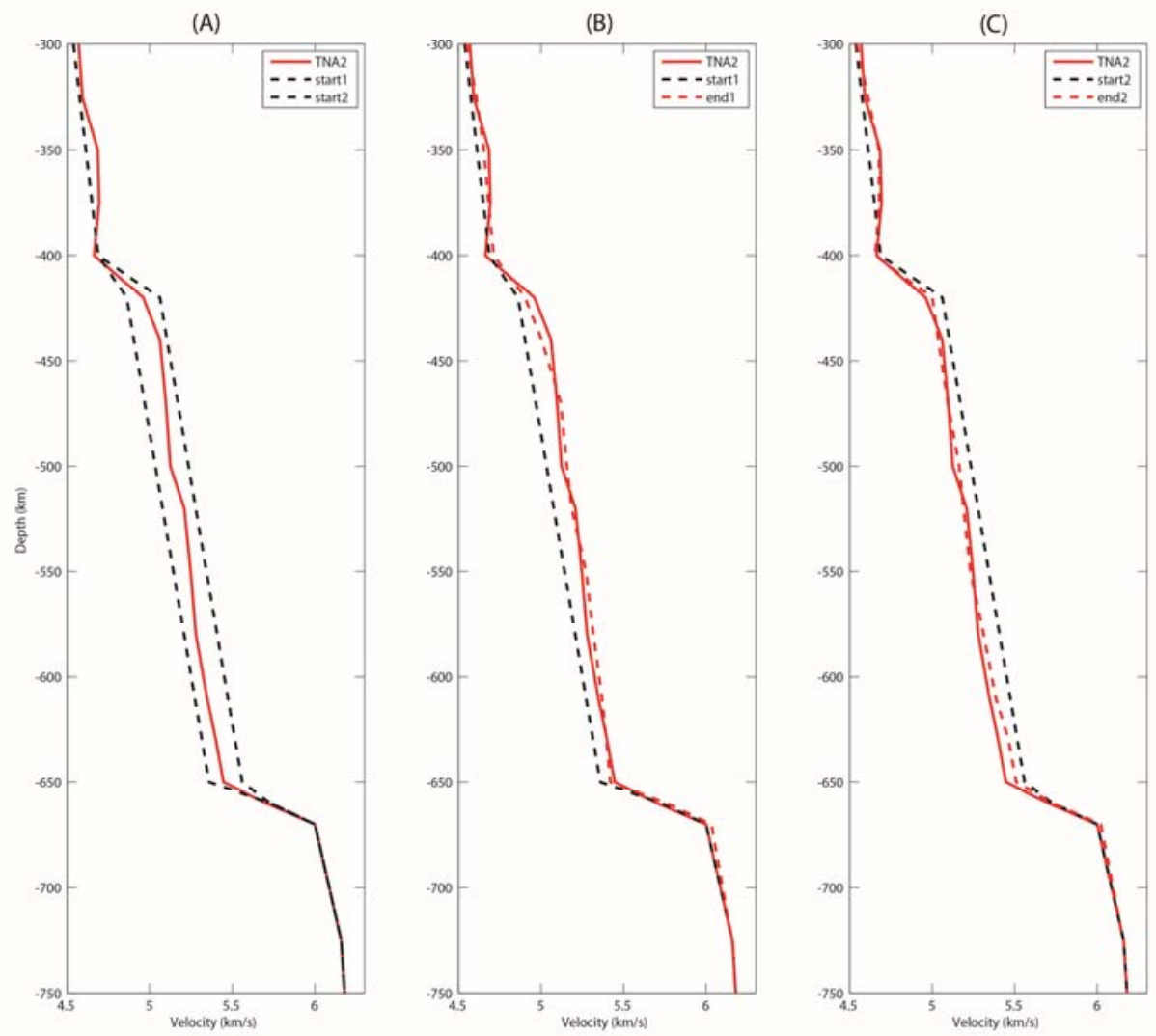

Figure 12. (A) The TNA2 model (red line) compared to two starting models (black dashed line) used to test the resolution of the inversion for discontinuity velocity jumps. (B) Comparison of model TNA2 (red line) with the low velocity starting model (black dashed line) and the inversion result (red dashed line). (C) Compares the TNA2 model (red line) to the high velocity starting model (black dashed line) and the inversion result (red dashed line).

Turning waves are not sensitive to the depth change within several tens of kilometers. We use the discontinuity depths from TNA model (Grand and Helmberger, 1984) in our starting model-- $410 \mathrm{~km}$ and $660 \mathrm{~km}$ respectively. One is because it samples the same area 
as TNA2 does; the other reason is that $410 \mathrm{~km}$ and $660 \mathrm{~km}$ are the common accepted depth for these two discontinuities globally, according to more reliable results from SS

precursors study such as Flanagan and Shearer, (1998), and Shearer and Masters, (1992). 


\section{Chapter 6: Discussion}

Shear velocity model TNA2 was derived from data sampling beneath the East Pacific Rise and western North America. It is significantly different in the transition zone from global reference models and a natural question to ask is how representative it is for the Earth. Global tomography models show variable transition zone anomalies for the region TNA2 samples. For example, beneath our study area, model S40RTS (Ritsema et al., 2011) shows slightly slower transition zone velocities than normal at $600 \mathrm{~km}$ depth while model SAW642AN (Panning and Romanowicz, 2006) shows slightly faster than normal shear velocity. In any case, most global tomography models have low amplitude shear velocity anomalies in the transition zone beneath this region and thus there is no indication that TNA2 represents an anomalous transition zone structure. Short wavelength transition zone heterogeneity has been imaged beneath the western United States using Earthscope data by several workers (e.g. Schmandt and Humphreys, 2010). For this reason we inverted three profiles of data that sampled the western United States from west to east. The fact that the inversions produced very similar models in the transition zone (figure 6) leads us to believe our vertical profiles of transition zone shear velocity are not biased by short wavelength heterogeneity. It is likely the short wavelength anomalies produce very small time anomalies that may be averaged out in our stacking process.

We compare the TNA2 model with the seismic velocities predicted by several mineral physics models (figure13). Li et al. (2007) predict mantle shear velocities by finite strain theory extrapolation from ultrasonic measurements in a frequency range of 20 $80 \mathrm{MHz}$ in a multi-anvil apparatus and $800-1000 \mathrm{MHz}$ in a diamond anvil apparatus. Irifune et al., (2008) combined in situ X-ray and ultrasonic measurements on realistic mantle compositions under pressure and temperature conditions of the mantle transition region. The velocity of shear waves was determined by a pulse-echo method using a 
transfer function. The frequency Irifune et al., (2008) used is $40 \mathrm{MHz}$. Finally, Xu et al., (2008) calculated shear velocities for various compositions and temperatures using a thermodynamic formalism. We use their equilibrium assemblage model for a basalt fraction of $18 \%$ along a $1600^{\circ} \mathrm{K}$ adiabat. Their calculations do not account for anelastic effects and thus are appropriate for infinite frequency. TNA2 was developed using data with a peak period of roughly 15 secs and thus to compare to mineral physics results we must consider the dispersion effects of anelasticity. We applied an approximate formula, given by Anderson, (1989) to correct the mineral physics predictions of velocity directly to TNA2 velocities. The formula is

$1-\frac{\mathrm{V}(\mathrm{P}, \mathrm{T}, \omega)}{\mathrm{V}(\mathrm{P}, \mathrm{T}, \infty)}=\frac{1}{2} \cot \left(\frac{\alpha \pi}{2}\right) \mathrm{Q}^{-1}(\mathrm{P}, \mathrm{T}, \omega)$

where $\omega$ is frequency and $\mathrm{V}$ is phase velocity at frequency $\omega$, pressure $\mathrm{P}$ and temperature $\mathrm{T}, \mathrm{Q}$ is the attenuation at frequency $\omega$, and $\alpha$ determines the frequency dependence of $\mathrm{Q}$. We used the Q model given in PREM (Dziewonski and Anderson, 1981) in our corrections. We took $\alpha$ to be .2 which is on the low end of measurement but which best aligned our seismic model with the mineral physics predictions. Small variations in temperature, possibly water content, and uncertainties in Q could all contribute to shifting the predicted velocity curves so absolute values are not as important as the discontinuity sizes and gradients which are less affected by our choice of $\alpha$.

The comparison of mineral physics predicted seismic models with model TNA2 shown in figure 13 shows excellent agreement within the transition zone, especially when compared to the same comparison with older seismic models shown in figure 1. In particular, TNA2 has the same overall increase in velocity at the $410 \mathrm{~km}$ discontinuity as predicted by Li and Liebermann, (2007) and Xu et al. (2008). The study by Irifune et al. (2008) did not include predictions of velocity above $410 \mathrm{~km}$ or below $660 \mathrm{~km}$. Equally important, the gradient in shear velocity of model TNA2 also agrees well with the mineral physics predictions within the small differences among the different mineral 
physics models for the pyrolite composition. Irifune et al. (2008) also shows a prediction of shear velocity for piclogite that clearly does not agree with model TNA2. Below 660 $\mathrm{km}$ depth the mineral physics predicted velocities do not agree. The Li and Liebermann, (2007) model closely matches model TNA2 but the predicted velocities of Xu et al., (2008) are significantly lower than TNA2 below the $660 \mathrm{~km}$ discontinuity. We have not explicitly discussed the resolution below $660 \mathrm{~km}$ depth but turning waves from $720 \mathrm{~km}$ and deeper are first arrivals in the SS waveforms and thus average velocity in this depth range is well constrained over $50 \mathrm{~km}$ or so. We conclude that a pyrolite composition along a $1600^{\circ} \mathrm{K}$ adiabat is consistent with mantle shear velocities beneath western North America and the East Pacific Rise from $330 \mathrm{~km}$ depth to $660 \mathrm{~km}$ depth. Discrepancies between the mineral physics predictions for pyrolite are large at greater depths such that it is not possible to conclude anything about the deeper composition and mineralogy.

Cammarano et al. (2005b) and Cammarano et al. (2009) have also examined the consistency of seismic models and chemical models of the upper mantle. In their work they use a global set of first arrival times, SS precursor data as well as normal mode data for seismic constraints. They use the work of Xu et al., (2008) as the basis for their mineralogy comparisons with the seismic data. They conclude that an increase of basalt fraction is necessary to match seismic shear velocity gradients near $250 \mathrm{~km}$ depth but that a model close to pyrolite is consistent with seismic data to $660 \mathrm{~km}$ depth. In the lower mantle they find the seismic data at odds with the slow seismic velocities predicted for pyrolite (figure 14) similar to what is shown in figure 13. We conclude that model TNA2, a high resolution transition zone model for one location, is likely consistent with global data sets such as those Cammarano et al. (2005b, 2009) used. 


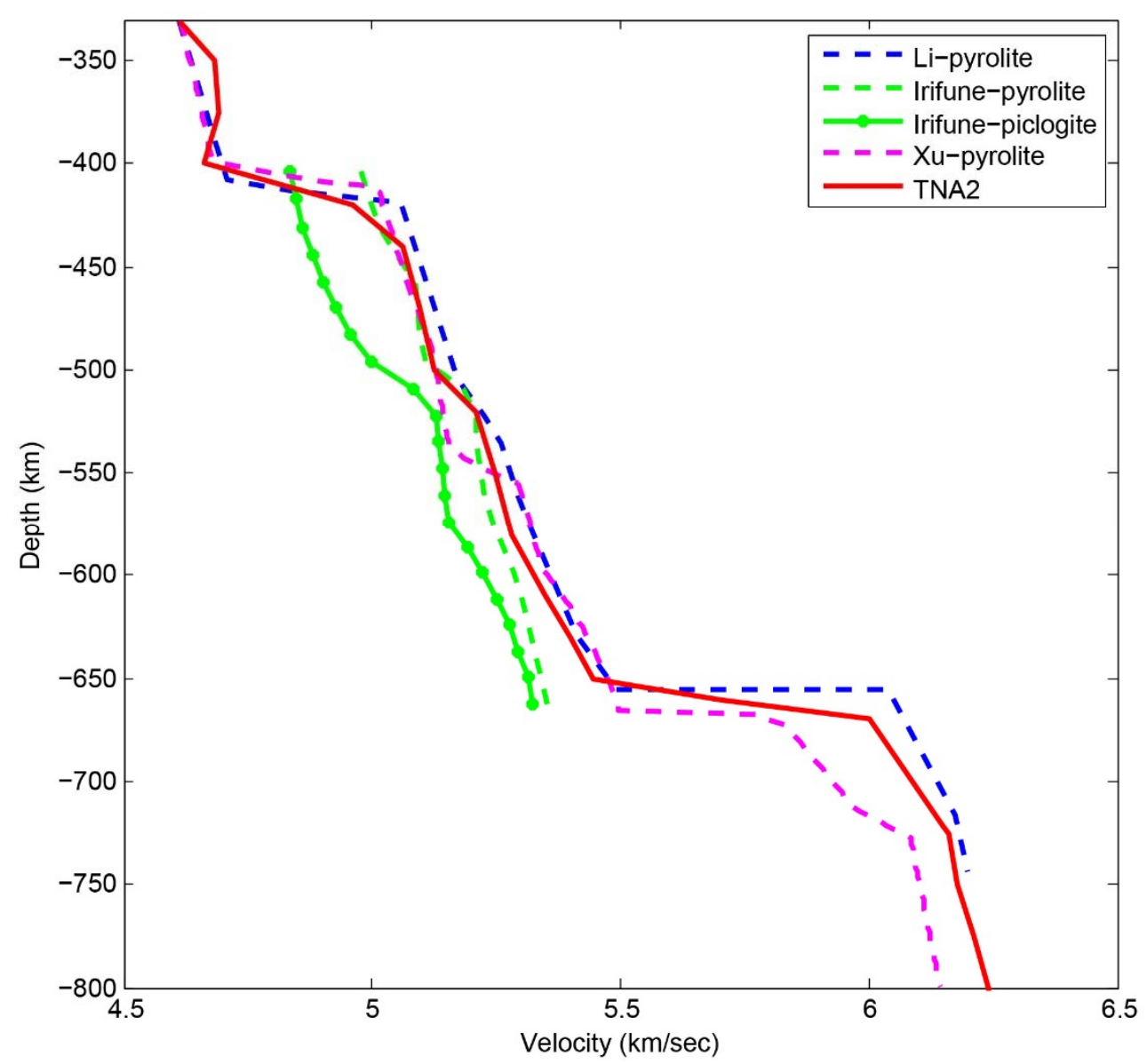

Figure 13. Comparison of shear velocity model (red solid line) TNA2 with predictions of shear velocity assuming a pyrolite composition along a $1600^{\circ} \mathrm{K}$ adiabat. The green dashed line is the prediction from Irifune et al., (2008), the purple dashed line is from Xu et al., (2008) and the blue dashed line is from Li et al., (2007). A prediction of shear velocity assuming a piclogite compostion from Irifune at al. (2007) is also shown as a solid green line. 


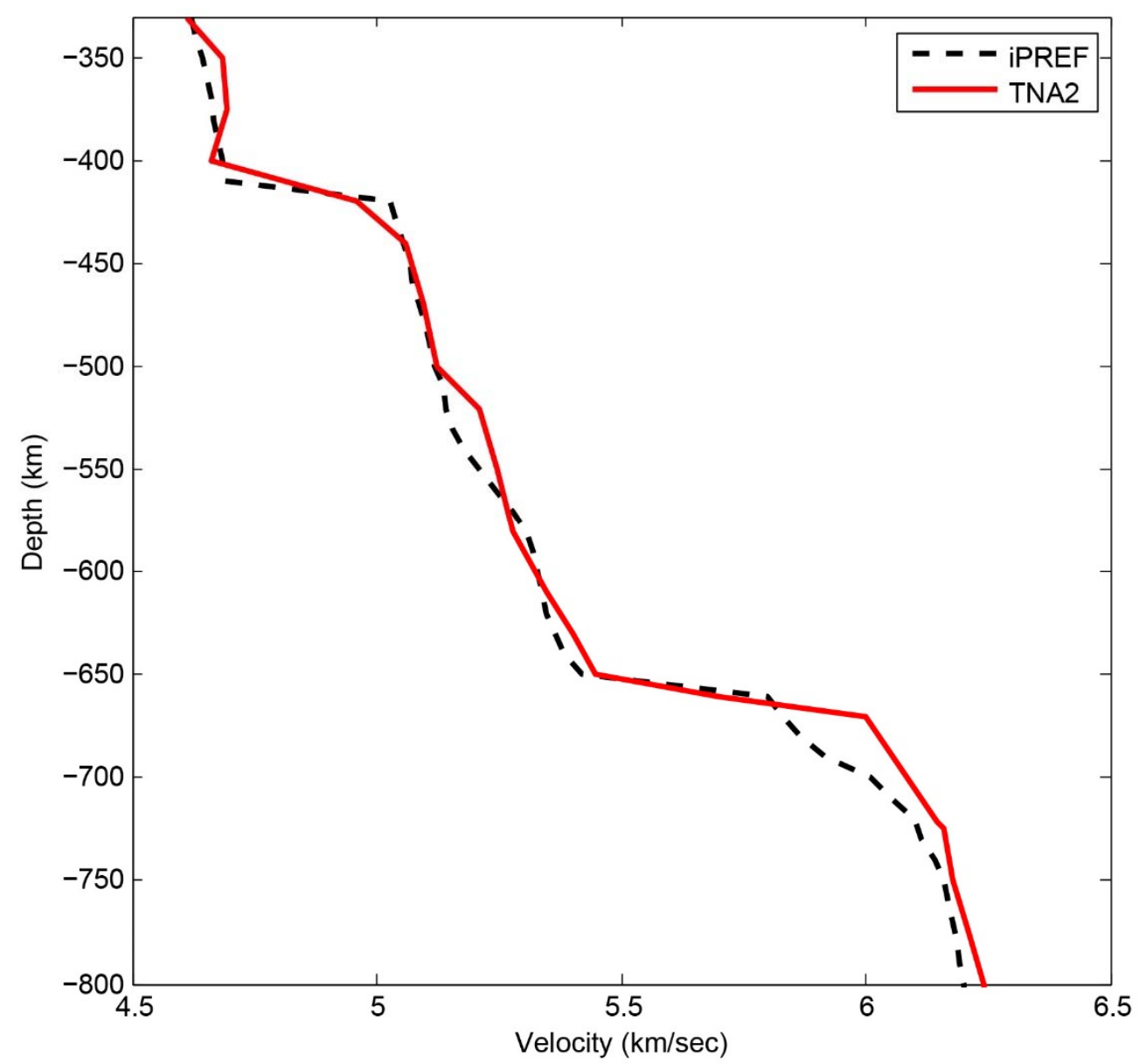

Figure 14. Comparison of model TNA2 (red line) with the iPREF model (Cammarano et al., 2009) (dark dashed line). 


\section{Chapter 7: Conclusion}

Seismic turning waves recorded by large aperture arrays provide good resolution for shear velocity structure within the mantle transition zone including vertical gradients and discontinuity sizes. With the application of a waveform inversion technique, our results for several profiles near the East Pacific Rise show mostly identical shear velocity structure in the mantle transition zone. The model we derived, TNA2, is consistent with mineral physics predictions using a pyrolite composition along a $1600 \mathrm{~K}$ adiabat from $350 \mathrm{~km}$ depth to the $660 \mathrm{~km}$ discontinuity. This consistency has been lacking before using older reference models. The difference in seismic models is likely due to a lack of resolution due to the standard seismic data sets used in the past. More studies using large aperture arrays in different regions are needed to see how representative model TNA2 is for the Earth.

Below $660 \mathrm{~km}$ depth there is a significant difference between model TNA2 and velocities predicted by $\mathrm{Xu}$ et al. (2008) for a pyrolite composition mantle along a $1600^{\circ} \mathrm{K}$ adiabat. Cammarano et al. (2009) found the same discrepancy. There are also differences between published predictions among mineral physicists pointing to the need for better mineral physics data for the relevant minerals at these pressures and temperatures. Currently, it is not possible to explain the discrepancy with simple temperature - composition models. 


\section{Table}

\begin{tabular}{|l|l|l|l|l|l|l|l|l|}
\hline$\#$ & Time & Latitude & Longitude & Depth & $\begin{array}{l}\text { Magnitude } \\
(\mathrm{Mw})\end{array}$ & Strike & Dip & Slip \\
\hline A & $\begin{array}{l}2006 / 11 / 19, \\
18: 57: 37.9\end{array}$ & -4.54 & -104.85 & 17.1 & 6.1 & 8 & 85 & 179 \\
\hline B & $2007 / 08 / 04$, & -4.60 & -105.68 & 15.6 & 6.1 & 11 & 89 & 172 \\
& $14: 25: 01.3$ & & & & & & & \\
\hline C & $\begin{array}{l}2008 / 09 / 18, \\
01: 41: 03.0\end{array}$ & -4.55 & -106 & 11 & 5.7 & 10 & 87 & 169 \\
\hline
\end{tabular}

Table 1. Parameters of the three earthquakes from the Harvard Centroid Moment Tensor (HRV). 


\begin{tabular}{|c|c|}
\hline Depth (km) & Velocity $(\mathrm{km} / \mathrm{sec})$ \\
\hline 0 & 3.45 \\
\hline 8 & 4.3 \\
\hline 50 & 4.3127 \\
\hline 75 & \begin{tabular}{|l|}
4.2001 \\
\end{tabular} \\
\hline 100 & 4.1733 \\
\hline 125 & 4.2033 \\
\hline 150 & 4.2821 \\
\hline 175 & 4.3552 \\
\hline 200 & 4.3744 \\
\hline 225 & 4.3929 \\
\hline 250 & 4.424 \\
\hline 275 & \begin{tabular}{|l}
4.4699 \\
\end{tabular} \\
\hline 300 & 4.55 \\
\hline 325 & 4.5923 \\
\hline 350 & 4.6849 \\
\hline 375 & \begin{tabular}{|l}
4.6931 \\
\end{tabular} \\
\hline 400 & 4.6632 \\
\hline 420 & 4.9601 \\
\hline 440 & 5.0614 \\
\hline 470 & 5.097 \\
\hline 500 & \begin{tabular}{|l|l|}
5.1244 \\
\end{tabular} \\
\hline 520 & 5.2188 \\
\hline 550 & 5.267 \\
\hline 580 & 5.2992 \\
\hline 610 & \begin{tabular}{|l}
5.3569 \\
\end{tabular} \\
\hline 630 & 5.42 \\
\hline 650 & 5.487 \\
\hline
\end{tabular}




\begin{tabular}{|l|l|}
\hline 660 & 5.7 \\
\hline 670 & 6 \\
\hline 721 & 6.1476 \\
\hline 725 & 6.1594 \\
\hline 750 & 6.1792 \\
\hline 775 & 6.2096 \\
\hline 800 & 6.24 \\
\hline 825 & 6.26 \\
\hline 850 & 6.275 \\
\hline 875 & 6.29 \\
\hline 900 & 6.305 \\
\hline 925 & 6.32 \\
\hline 950 & 6.335 \\
\hline 975 & 6.35 \\
\hline 1000 & 6.365 \\
\hline
\end{tabular}

Table 2. TNA2 model 


\section{References}

1. Ai, Y., and Zheng, T., (2003). The upper mantle discontinuity structure beneath eastern China, Geophys. Res. Lett. 30(21), 2089-2093.

2. Anderson, D. L. (1989). Theory of the Earth, Blackwell Sci., Malden, Mass.

3. Anderson, D. L., and Bass, J. D., (1984). Mineralogy and composition of the upper mantle, Geophys. Res. Lett. 11, 637-640.

4. Bass, J. D., and Anderson, D. L., (1984). Composition of the upper mantle: geophysical tests of two petrological models, Geophys. Res. Lett. 11(3), 237-240.

5. Bina, C. R., and Helffrich, G., (1994). Phase transition Claperon slopes and transition zone seismic discontinuity topography, J. Geophys. Res. 99, 15,853 - 15,860.

6. Bina, C. R., and Wood, B. J., (1987). The olivine-spinel transitions: Experimental and thermodynamic constraints and implications for the nature of the $400 \mathrm{~km}$ seismic discontinuity, J. Geophys. Res. 92, 4853-4866.

7. Brandt, M., Grand, S., Nyblade, A., and Dirks, P.,(2011). Upper mantle seismic structure beneath Southern Africa: Constraints on the buoyancy supporting the African superswell, Pure Appl. Geophys., DOI 10.1007/s00024-011-0361-8.

8. Cammarano, F., Goes, S., Vacher, P., and Giardini, D., 2003. Inferring upper mantle temperatures from seismic velocities, Phys. Earth Planet. Inter. 139, 197-222.

9. Cammarano, F., Goes, S., Deuss, A., Giardini, D., 2005a. Is a pyrolitic adiabatic mantle compatible with seismic data?, Earth Planet. Sci. Lett., 232, 227-243.

10. Cammarano, F., Deuss, A., Goes, S., Giardini, D., 2005b. One-dimensional physical reference models for the upper mantle and transition zone: Combining seismic and mineral physics constraints, J. Geophys. Res., 110(B1), B01306.

11. Cammarano, F., Romanowicz, B., Stixrude, L., Lithgow-Bertelloni, C., and Xu, W., 2009. Inferring the thermochemical structure of the upper mantle from seismic data, Geophys. J. Int. $179,1169-1185$.

12. Deuss, A., and Woodhouse, J., (2001). Seismic observations of splitting of the midtransition zone discontinuity in the earth's mantle, Science, 294, 354-357. 
13. Deuss A., Redfern, S. A. T., Chambers, K., Woodhouse, J. H., 2006. The nature of the 660-kilometer discontinuity in earth's mantle from global seismic observations of PP precursors, Science, 311(5758), 198-201.

14. Dueker, K. G., and Sheehan, A. F., 1997. Mantle discontinuity structure from midpoint stacks of converted P and S waves across the Yellowstone hotspot track, J. Geophys. Res. 103(B4), 8313-8327.

15. Dziewonski, A., and Anderson, D., 1981. Preliminary reference Earth model, Phys. Earth Planet. Inter., 25, 297-356.

16. Flanagan, M., and Shearer, P., 1998. Global mapping of topography on transition zone velocity discontinuities by stacking SS precursors, J. Geophys. Res. 103(B2), 2673-2692.

17. Fuchs and Muller, 1971. Computation of synthetic seismograms with the reflectivity method and comparison with observation, Geophys. J. R. Astron. Soc. 23, 417-433.

18. Fukao, Y., Widiyantoro S., and Obayashi, M., 2001. Stagnant slabs in the upper and lower mantle transition region, Rev. Geophys. 39(3), 291-323.

19. Gao, W., Matzel, E., and Grand, S., 2006. Upper mantle seismic structure beneath eastern Mexico determined from P and S waveform inversion and its implications, J. Geophys. Res. 111, B08307.

20. Grand, S. P., and Helmberger, D., 1984. Upper mantle shear structure of North America, Geophys. J. R. Astron. Soc., 76, 399-438.

21. Grand, S. P. 1994, Mantle shear structure beneath the Americas and surrounding oceans, J. Geophys. Res. 99(B6), 11,591-11,621.

22. Gu, Y.J., Dziewonski, A.M., Su,W.-J., and Ekstr”om, G., 2001. Models of the mantle shear velocity and discontinuities in the pattern of lateral heterogeneities, J. Geophys. Res.106, 11,169-11,199.

23. Ita, J. and Stixrude, L., 1992. Petrology, elasticity and composition of the transition zone. J. Geophys. Res., 97(B5), 6849-6866.

24. Jasbinsek, J. J., Dueker, K. G. and Hansen, S. M., 2010. Characterizing the $410 \mathrm{~km}$ discontinuity low-velocity layer beneath the LA RISTRA array in the North American Southwest, Geochem. Geophys. Geosyst., 11, Q03008.

25. Kennett, B. L., Engdahl, E. R. and Buland, R., 1995. Constraints on seismic velocities in the Earth from travel times, Geophys. J. Int. 122, 108-124.

26. Li, B., Liebermann, R. C., and Weidner, D. J., 1998. Elastic Moduli of Wadsleyite 37 
(b-Mg2SiO4) to 7 Gigapascals and 873 Kelvin, Science, 281, 675-677.

27. Li, B., and Liebermann, R. C., 2007. Indoor Seismology by probing the Earth's interior by using sound velocity measurements at high pressures and temperatures, PNAS, 104(22), 9145-9150.

28. Liu, W., Kung, J., Li, B., 2005. Elasticity of San Carlos olivine to 8 GPa and 1073 K, Geophys. Res. Lett. 32, L16301.

29. Marone, F., Van der Lee, S., and Giardini, D., 2004 Shallow anisotropy in the Mediterranean mantle from surface waves, Geophys. Res. Lett. 31, L06624.

30. Matzel, E., 2002. The anisotropic seismic structure of the Earth's mantle: Investigations using full waveform inversion, dissertation, Univ. of Tex. at Austin, Austin.

31. Matzel, E., and Grand, S., 2004. The anisotropic seismic structure of the East European platform, J. Geophys. Res. 109, B01302.

32. Mora, P., 1987. Nonlinear two-dimensional elastic inversion of multioffset seismic data, Geophys. 52(9), 1211-1228.

33. Nolet, G., Grand, S., and Kennet, B., 1994. Seismic heterogeneity in the upper mantle, J. Geophys. Res., 99, 23,753-23,766.

34. Panning, M. P., and Romanowicz, B. A., 2006. A three dimensional radially anisotropic model of shear velocity in the whole mantle, Geophys. J. Int., 167, 361-379.

35. Revenaugh, J., and Sipkin, S. A., 1994. Mantle discontinuity structure beneath China. J. Geophys. Res. 99(B11), 21,911-21,927.

36. Ringwood, A. E., 1975. Composition and petrology of the earth's mantle, McGraw-Hill, New York.

37. Ritsema, J. E., Deuss, A., Van Heijsst, H. J., Woodhouse, J. H., 2011. S40RTS: a degree40 shear-velocity model for the mantle from new Rayleigh wave dispersion, teleseismic traveltime and normal-mode splitting function measurements. Geophys. J. Int. doi:10.1111/j.1365-246X.2011.04921.x.

38. Romanowicz, B. and Gung, Y. C., 2002. Superplumes from the core-mantle boundary to the lithosphere: implications for heat flux, Science, 296, 513-516.

39. Schmandt, B. and Humphreys, E. D., 2010. Complex subduction and small-scale convection revealed by body wave tomography of the western U.S. upper mantle. Earth Planet. Sci. Lett. 297, 435-445. 
40. Sen, M.K., and Stoffa, P. L., 1995. Global Optimization Methods in Geophysical Inversion, as part of Advances in Exploration Geophysics series, Elsevier Publishing Co.

41. Shearer, P. M., 1990. Seismic imaging of upper-mantle structure with new evidence for a 520-km discontinuity, Nature, 344, 121-126.

42. Shearer, P.M. and Masters, T. G., 1992. Global mapping of topography on the $660 \mathrm{~km}$ discontinuity, Nature, 355, 791-796.

43. Shearer, P. M., 1993. Global mapping of upper mantle reflectors from long-period SS precursors, Geophys. J. Int., 115, 878-904.

44. Shearer, P. M., and Flanagan, M. P., 1999. Seismic velocity and density jumps across the 410- and 660-kilometer discontinuities, Science, 285, 1545-1548.

45. Song, T. A., Helmberger, D. V., Grand, S. P., 2004. Low-velocity zone atop the 410-km seismic discontinuity in the northwestern United States, Nature. 427, 530-533.

46. Irifune, T., Higo, Y., Inoue, T., Kono, Y., Ohfuji, H., Funakoshi, K., 2008. Sound velocities of majorite garnet and the composition of the mantle transition region, Nature. 451, 814-817.

47. Walck, M. C., 1984. The P-wave upper mantle structure beneath an active spreading center-the Gulf of California, Geophys. J. R. Astron. Soc. 76, 697-723.

48. Weidner, D. J. and Ito, E., 1987. Mineral physics constraints on a uniform mantle composition, In: High-Pressure Research in Mineral Physics, eds., M. H. Manghnani and Y. Syono, TERRA PUB/Am. Geophys. Union, Tokyo/Washington D. C., 439-446.

49. Xu, W., Lithgow-Bertelloni, C., Stixrude, L., Ritsema, J., 2008. The effect of bulk composition and temperature on mantle seismic structure, Earth. Planet. Sci. Lett. $275,70-79$. 